ALEXANDRE KOPTE GARCIA

\title{
AVALIAÇÃO DA ATIVIDADE LIPOLÍTICA DE FUNGOS FILAMENTOSOS
}

\section{DA COSTA BRASILEIRA}

Dissertação apresentada ao Programa de PósGraduação Interunidades em Biotecnologia USP/Instituto Butantan/IPT, para obtenção do Título de Mestre em Biotecnologia. 
ALEXANDRE KOPTE GARCIA

AVALIAÇÃO DA ATIVIDADE LIPOLÍTICA DE FUNGOS FILAMENTOSOS DA COSTA BRASILEIRA

Dissertação apresentada ao Programa de PósGraduação Interunidades em Biotecnologia USP/Instituto Butantan/IPT, para obtenção do Título de Mestre em Biotecnologia.

Área de concentração: Biotecnologia

Orientadora: Dra. Lara Durães Sette 
DADOS DE CATALOGAÇÃO NA PUBLICAÇÃO (CIP)

Serviço de Biblioteca e Informação Biomédica do

Instituto de Ciências Biomédicas da Universidade de São Paulo

(c) reprodução total

\section{Garcia, Alexandre Kopte.}

Avaliação da atividade lipolítica de fungos filamentosos da costa brasileira / Alexandre Kopte Garcia. -- São Paulo, 2010.

Orientador: Lara Durães Sette.

Dissertação (Mestrado) - Universidade de São Paulo. Instituto de Ciências Biomédicas. Departamento de Biologia Celular e do Desenvolvimento. Área de concentração: Biotecnologia. Linha de pesquisa: prospecção de enzimas produzidas por fungos.

Versão do título para o inglês: Evaluation of the lipolytic activity of filamentous fungi from the Brazilian coast.

Descritores: 1. Biotecnologia 2. Enzimas 3. Fungos 4. Biorremediação 5. Lipase 6. Emulsificantes I. Sette, Lara Durães II. Universidade de São Paulo. Instituto de Ciências Biomédicas. Programa de Pós-Graduação Interunidades em Biotecnologia USP/IPT/Instituto Butantan. III. Título. 
Candidato(a):

Título da Dissertação:

Orientador(a):
Alexandre Kopte Garcia.

Avaliação da atividade lipolítica de fungos filamentosos da costa brasileira .

Lara Durães Sette.

A Comissão Julgadora dos trabalhos de Defesa da Dissertação de Mestrado, em sessão pública realizada a ....................................
( ) Aprovado(a)
( ) Reprovado(a)

Examinador(a): Assinatura:

Nome:

Instituição:

Examinador(a): Assinatura:

Nome:

Instituição:

Presidente: Assinatura:

Nome:

Instituição: 
Dedico este trabalho à memória de Helga Kopte Garcia, Johanna Martha Kopte e Maria Rosa Fernandes de Benito Garcia. 


\section{AGRADECIMENTOS}

A todos das divisões de Recursos Microbianos, Microbiologia e Fitoquímica do Centro Pluridisciplinar de Pesquisas Químicas, Biológicas e Agrícolas (CPQBA) da UNICAMP pelo convívio e ajuda.

A Dra. Lara Durães Sette pela orientação, paciência e ensinamentos.

Ao Conselho Nacional de Desenvolvimento Científico e Tecnológico (CNPq) pela bolsa de estudos e a Fundação de Amparo à Pesquisa do Estado de São Paulo (FAPESP) pelo apoio financeiro (projeto temático).

Aos familiares e amigos que me apoiaram e incentivaram de alguma forma.

Muito obrigado! 


\section{RESUMO}

GARCIA, A. K. Avaliação da atividade lipolítica de fungos filamentosos da costa brasileira. 2011. 55 f. Dissertação (Mestrado em Biotecnologia) - Instituto de Ciências Biomédicas, Universidade de São Paulo, São Paulo, 2011.

A produção de compostos biologicamente ativos por micro-organismos marinhos tem atraído crescente interesse de biotecnólogos e microbiologistas nas últimas décadas, uma vez que os oceanos cobrem mais de $70 \%$ da superfície do planeta e constituem ambientes pouco explorados em relação a sua biodiversidade e recursos genéticos. A grande maioria dos compostos provenientes de fungos derivados de ambientes marinhos foi encontrada em fungos associados a invertebrados como esponjas, algas, tunicados e moluscos. Portanto, especula-se que muitos dos compostos de interesse biotecnológico encontrados em invertebrados marinhos sejam na verdade produzidos pela microbiota associada. Entre as biomoléculas pesquisadas, uma das que mais chama atenção são as lipases, devido a sua vasta gama de aplicações em diversos setores industriais, e também no ambiente. No presente trabalho 162 isolados de fungos filamentosos recuperados de amostras de água do mar e de dez diferentes macro-organismos marinhos (Amphimedon viridis, Axinella corrugata, Chelonaplysilla erecta, Codium intertextum, Didemnum sp., Dragmacidon reticulata, Echinaster brasiliensis, Mycale laxissima, Petromica citrina e uma estrela do mar não identificada) foram avaliados quanto a produção de lipases pelo método de High Throughput Screening (HTS). Destes, 45 isolados tiveram a produção de lipases confirmada individualmente, cerca de $28 \%$ dos fungos avaliados. Os invertebrados Didemnum sp., D. reticulata e A. viridis foram os que derivaram o maior número de fungos lipolíticos, totalizando 36 isolados. A atividade lipolítica foi quantificada, e os resultados sugerem que fungos filamentosos oriundos de ambientes marinhos tem maior potencial para produção de lipases estáveis em $\mathrm{pH}$ alcalino. Sete isolados apresentaram atividade de lipase maior que $1 \mathrm{U}$ em pH 8,0 e foram identificados e depositados na Coleção Brasileira de micro-organismos de Ambiente e Indústria (CBMAI). Entre estes, Fusarium sp. CBMAI 1227, Aspergillus parasiticus CBMAI 1228 e Trichoderma sp. CBMAI 1229 apresentaram atividade expressiva e de interesse biotecnológico em pH 8,0 (23,1, 12,7 e 12,2 U respectivamente). Adicionalmente, os três isolados passaram por avaliação da atividade emulsificante, porém, não apresentaram resultados significativos, justificando a realização de novos estudos acerca da produção destes compostos por fungos filamentosos de origem marinha. Os resultados 
deste trabalho demonstram o potencial dos fungos provenientes de ambiente marinho para aplicações biotecnológicas, e estimulam novos estudos de caracterização enzimática, detecção e caracterização de genes que codificam para a produção de lipases, bem como de otimização e produção destas enzimas em escala industrial.

Palavras-chave: Fungos marinhos. Bioprospecção. Lipase. Emulsificante. Biorremediação. 


\begin{abstract}
GARCIA, A. K. Evaluation of the lipolytic activity of filamentous fungi from the Brazilian coast. 2011. 55 p. Master thesis (Biotechnology) - Instituto de Ciências Biomédicas, Universidade de São Paulo, São Paulo, 2011.

The production of biologically active compounds by marine microorganisms has been drawing increasing interest of biotechnologists and microbiologists in the last decades, since the oceans cover more than $70 \%$ of the planet's surface and are underexplored in relation to their biodiversity and genetic resources. Most of the compounds from marine-derived fungi were found in fungi associated to invertebrates such as sponges, algae, tunicates and mollusks. Thereby, it has been speculated that many of the biotechnologically-interesting compounds found in marine invertebrates are in fact produced by the associated microorganisms. Among the studied biomolecules, one that draws greater attention is the lipase, due to their wide range of applications in many industries, and in the environment as well. In the present work 162 filamentous fungi isolates recovered from water samples and ten different marine macroorganisms (Amphimedon viridis, Axinella corrugata, Chelonaplysilla erecta, Codium intertextum, Didemnum sp., Dragmacidon reticulata, Echinaster brasiliensis, Mycale laxissima, Petromica citrina and one unidentified starfish) were evaluated for the production of lipases by the method of High Throughput Screening (HTS). Out of those, 45 had the lipase production individually confirmed, about $28 \%$ of the total fungi studied. The macroorganisms Didemnum sp., D. reticulata and A. viridis were the ones that derived the greatest number of lipolytic fungi, totalizing 36 isolates. The lipolytic activity was quantified, and the results suggest that marine-derived filamentous fungi have a greater potential for the production of lipases stable under alkaline $\mathrm{pH}$. Seven isolates showed activity greater than $1 \mathrm{U}$ in $\mathrm{pH}$ 8,0 and were identified and deposited in the Brazilian Collection of Environmental and Industrial Microorganisms (CBMAI). Among these, Fusarium sp. CBMAI 1227, Aspergillus parasiticus CBMAI 1228 and Trichoderma sp. CBMAI 1229 showed expressive and biologically interesting activity in $\mathrm{pH} 8,0(23,1,12,7$ and 12,2 $\mathrm{U}$ respectively). Additionally, the three isolates had their emulsification activity evaluated, but did not show significant results, justifying new studies concerning the production of those compounds by marinederived fungi. The results of the present work show the potential of marine-derived fungi in biotechnological applications, and stimulate new studies of enzymatic characterization, lipaseencoding genes detection and characterization, as well as the optimization and production of those enzymes in industrial scale.
\end{abstract}

Keywords: Marine fungi. Bioprospection. Lipase. Emulsifier. Bioremediation. 


\section{SUMÁRIO}

1 INTRODUCÃ

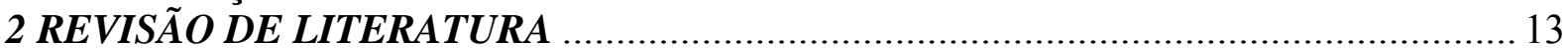

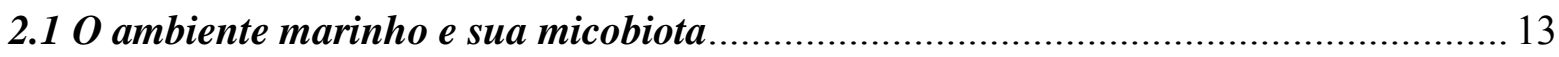

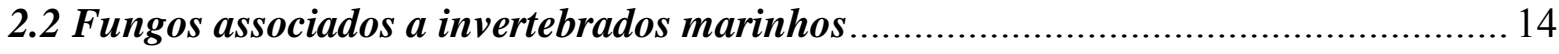

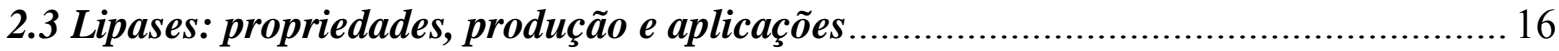

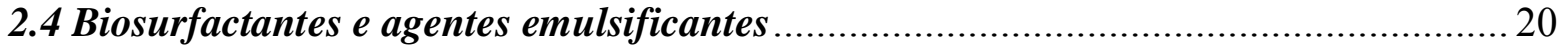

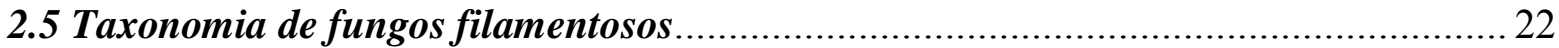

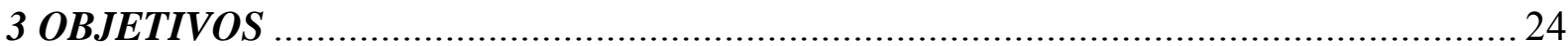

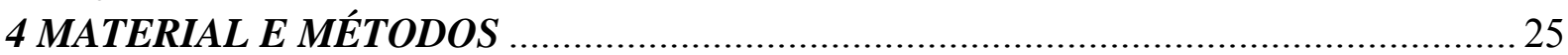

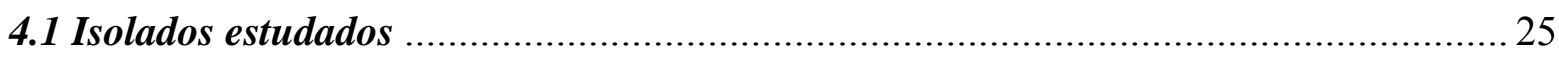

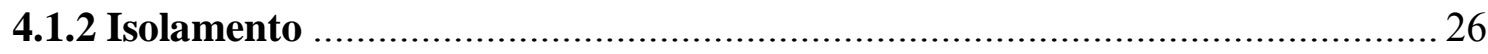

4.2 Avaliação e quantificação da produção de lipases .................................................. 27

4.2.1 High throughput screening-HTS de lipase ............................................. 27

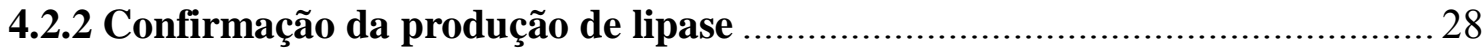

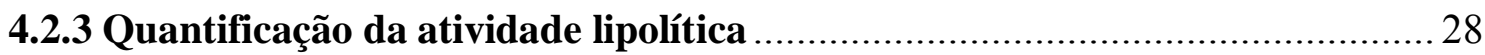

4.2.3.1 Preparo do inóculo e condições de cultivo ........................................... 28

4.2.3.2 Quantificação da atividade lipolítica.................................................. 29

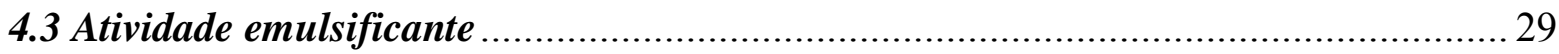

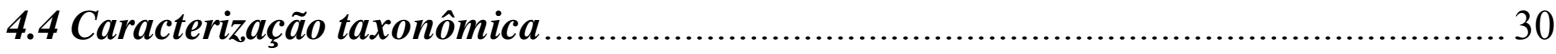

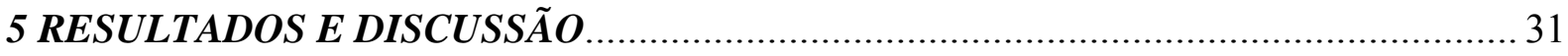

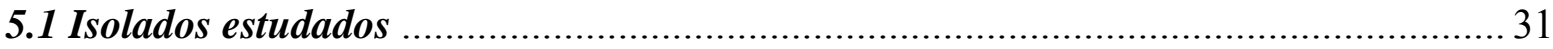

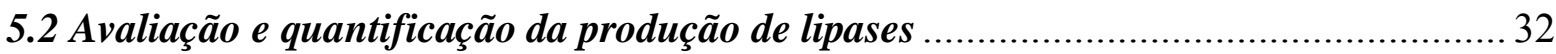

5.2.1 High throughput screening-HTS de lipase .............................................. 32

5.2.2 Confirmação da produção de lipase ......................................................... 33

5.2.3. Quantificação da atividade lipolítica e caracterização taxonômica............... 37

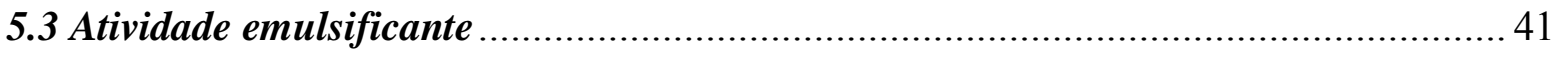

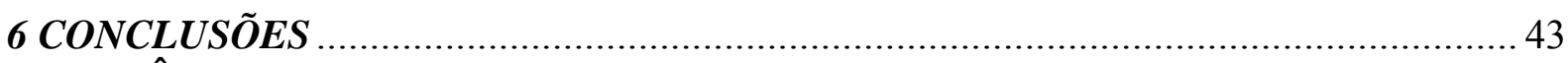

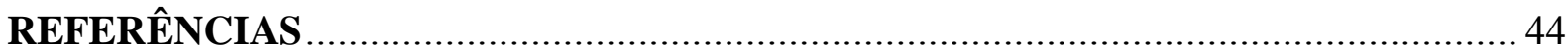

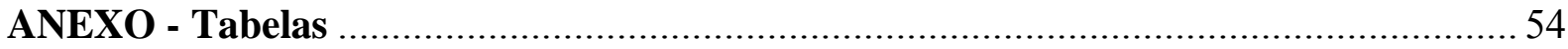




\section{INTRODUÇÃO}

Os micro-organismos derivados de ambientes marinhos transformaram-se em uma fonte muito importante de recursos genéticos para aplicação em biotecnologia, pois por pertencerem a ambientes ainda pouco explorados, podem representar a descoberta de novas drogas ou novos compostos de interesse. Devido ao fato de a micologia marinha ser uma ciência relativamente recente e de pouco se conhecer sobre a natureza biológica dos fungos marinhos, este grupo de organismos tem sido foco de estudos de biodiversidade e bioprospecção de compostos de interesse industrial.

Entre os compostos que despertam crescente interesse encontram-se as lipases. Estas são enzimas de grande potencial econômico com aplicações em diversos setores industriais, incluindo as indústrias alimentícias e de bebidas, química e farmacêutica, papeleira, cosmética, de couro, entre outras. Além das diversas aplicações das lipases, cabe ressaltar que o isolamento e seleção de micro-organismos de ambientes marinhos produtores destas enzimas, visando sua aplicação em processos de degradação de hidrocarbonetos resultantes de derramamento acidental nos oceanos, são estrategicamente muito interessantes, uma vez que estes organismos já estão adaptados às condições destes ambientes. Em contrapartida os fungos filamentosos derivados de ambientes marinhos são pouco estudados em relação à produção de lipases se comparados a bactérias e leveduras.

Surfactantes e emulsificantes são compostos que, assim como as lipases, tem diversas aplicações em setores como a indústria farmacêutica, de cosméticos, petrolífera e alimentícia, entre outras, além de encontrarem aplicação na bioremediação de hidrocarbonetos. Porém, a maioria dos surfactantes e emulsificantes conhecidos e utilizados é derivada do petróleo. Estes compostos não são facilmente biodegradados e sua produção gera subprodutos danosos ao meio ambiente. Os biosurfactantes e bioemulsificantes produzidos por micro-organismos apresentam uma série de vantagens sobre os sintéticos, além de atenderem a normas ambientais cada vez mais rígidas para diversas aplicações. Como são biodegradáveis, podem ser produzidos em larga escala por micro-organismos e não dependem do petróleo, podendo substituir os surfactantes sintéticos utilizados tradicionalmente em algumas aplicações. Entretanto, estudos avaliando a produção de surfactantes e emulsificantes por fungos filamentosos ainda são escassos, e em menor escala ainda os que envolvem fungos isolados de ambientes marinhos. 
Neste contexto, a Divisão de Recursos Microbianos do CPQBA/UNICAMP vem participando e desenvolvendo projetos de pesquisas que envolvem isolamento, avaliação do potencial biotecnológico, caracterização taxonômica e preservação de fungos derivados de ambientes marinhos, sob a Coordenação e/ou participação da Dra. Lara Durães Sette.

Encontram-se preservados em nosso laboratório (CBMAI/DRM CPQBA/UNICAMP), cerca de 800 isolados de fungos filamentosos recuperados de amostras marinhas (água do mar, invertebrados, alga, corais) da região de São Sebastião/Ilhabela-SP no âmbito dos projetos Fapesp 05/51213-8 "Fungos derivados de ambientes marinhos: isolamento, caracterização taxonômica e avaliação do potencial biotecnológico" (coordenado pela Dra. Lara D. Sette) e Temático Fapesp 05/60175-2 “Descoberta e desenvolvimento de potenciais agentes quimioterapêuticos a partir de invertebrados marinhos e de microorganismos associados" (processo 05/60175-2), sob coordenação do Dr. Roberto Gomes de Souza Berlinck (IQ-USP/SC), do qual este trabalho também faz parte.

Assim, o presente projeto utilizou fungos filamentosos derivados de ambiente marinho visando os seguintes objetivos: a) isolamento de fungos filamentosos a partir de amostras de água do mar e de macro-organismos marinhos; b) seleção de fungos lipolíticos; c) avaliação da produção e quantificação da atividade lipolítica produzida pelos isolados selecionados; d) avaliação da atividade de emulsificação dos isolados que apresentaram melhores resultados de atividade lipolítica e e) caracterização taxonômica dos isolados que apresentaram potencial para utilização em processos biotecnológicos. 


\section{REVISÃO DE LITERATURA}

\subsection{O ambiente marinho e sua micobiota}

Compreendendo mais de $90 \%$ da biosfera, o ecossistema marinho é o maior do planeta. Aproximadamente $71 \%$ da superfície terrestre encontram-se cobertos por águas oceânicas $-97 \%$ do volume total de água do planeta. A principal peculiaridade do ambiente marinho é a salinidade elevada, variando na faixa de 3,4 a 3,7\% em mar aberto, podendo chegar a mais de $30 \%$ em mares fechados. Entretanto, o que torna o ecossistema marinho realmente peculiar é o fato do mesmo reunir extremos de praticamente todas as variáveis ambientais: pressão, radiação, temperatura, $\mathrm{pH}$, concentração de oxigênio e nutrientes, entre outras (BAHARUM; BENG; MOKHTAR, 2010; MUNN, 2004; RAGHUKUMAR, 2005; RHEINHEIMER, 1987).

Devido à grande variação das características ambientais no ambiente marinho os micro-organismos se adaptaram e desenvolveram uma enorme diversidade metabólica, o que permitiu sua dispersão por todo tipo de habitat marinho: na superfície, livres na coluna d'água, aderidos a partículas, no sedimento, aderidos a superfícies de pedras, plantas, algas, animais ou estruturas fabricadas pelo homem, próximos a sistemas hidrotermais marinhos, nos mangues, e ainda no sistema digestivo e cavidades de vertebrados e invertebrados (MUNN, 2004; RHEINHEIMER, 1987). Paradoxalmente, o ambiente marinho visto atualmente como uma das mais promissoras fontes de novos organismos e propriedades exploráveis, foi um dos últimos dos ambientes a ser explorado por biotecnólogos e microbiologistas (BULL; WARD; GOODFELLOW, 2000; PROKSCH et al., 2003).

Os micro-organismos marinhos se tornaram uma importante fonte de compostos biologicamente ativos (DAVIES-COLEMAN; BEUKES, 2004; IMHOFF, 2004; JHA; ZIRONG, 2004; KELECOM, 2002; LIPTON, 2003; MAYER; HAMANN, 2004; MAYER; LEHMANN, 2000). Mais especificamente, os fungos de origem marinha demonstram grande potencial, como sugerido pela diversidade de metabólitos secundários produzidos pelos mesmos, e relatados na literatura (BUGNI; IRELAND, 2004; CRUZ et al., 2006; GESNER et al., 2005; SHIGEMORI et al., 2004). A pesquisa de fungos derivados de ambientes marinhos já levou a descoberta de mais de 272 novos compostos, incluindo muitos com estrutura única. Estes fungos são geralmente denominados fungos derivados de ambiente marinho. Isto se 
explica pelo fato de que o ambiente marinho compreende fungos obrigatoriamente marinhos e também espécies facultativas. Fungos marinhos obrigatórios crescem e esporulam somente em ambiente marinho, enquanto os facultativos habitam ambientes terrestres ou de água doce, mas também conseguem se desenvolver no ambiente marinho. De acordo com a estimativa relatada na literatura são conhecidas cerca de 1.500 espécies de fungos marinhos, sendo 800 desses fungos marinhos obrigatórios e dentre esses 465 fungos filamentosos (DAS; LAYLA; KHAN, 2006; BUGNI; IRELAND, 2004).

Os fungos são organismos eucariotos heterotróficos que tem importante papel na decomposição e ciclagem de nutrientes no ecossistema. O papel ecológico dos fungos de ambientes terrestres foi bastante descrito e conseqüentemente estudado, porém a ecologia de fungos marinhos têm sido mais difícil de ser compreendida. Estudos envolvendo a ecologia de fungos marinhos foram iniciados principalmente devido ao fato de muitas das espécies apresentarem patogenicidade. Além das espécies derivadas de ambientes marinhos, os estudos relatam que espécies terrestres e de água doce também têm efeitos no ecossistema marinho. Apesar de várias doenças e infecções no ambiente marinho estarem relacionadas aos fungos, também são conhecidas muitas relações de mutualismo entre fungos e outros organismos como corais, esponjas, algas e ascídias. A grande maioria dos compostos biologicamente ativos provenientes de fungos derivados de ambientes marinhos foram encontrados em fungos associados a algas e esponjas, e em menor grau a tunicados, moluscos e outros. O estudo dessas relações pode nos ajudar a compreender o ecossistema marinho e nos levar à descoberta de novos métodos de coleta e isolamento de espécies quimicamente inexploradas (DAS; LAYLA; KHAN, 2006; BUGNI; IRELAND, 2004).

Estudos relacionados à micro-organismos marinhos na costa brasileira são escassos. Os fungos filamentosos encontrados com maior incidência nestes estudos são representantes dos gêneros Aspergillus, Penicillium, Fusarium, Trichoderma, Paecilomyces, Cladosporium e Acremonium (BERLINCK et al., 2004; DA SILVA et al., 2008; MENEZES et al., 2010).

\subsection{Fungos associados a invertebrados marinhos}

Devido a seu habitat incomum quando comparados a organismos terrestres, os organismos marinhos como esponjas, corais, tunicados e briozoários metabolizam e produzem uma série de compostos que apresentam estruturas e atividades biológicas distintas e 
biotecnologicamente interessantes. Por outro lado, corais e esponjas são conhecidos por manterem relações simbióticas ou de parasitismo com micro-organismos como cianobactérias, fungos e bactérias, o que os torna um conglomerado em miniatura de vários organismos. A associação entre micro e macro-organismos é uma característica proeminente dos ecossistemas marinhos. Daí surge uma questão que vem sendo bastante estudada: quem realmente produz os compostos únicos e biologicamente ativos inicialmente isolados dos invertebrados como um todo? Para muitos organismos, especialmente esponjas, a natureza biológica dessas associações nunca foi rigorosamente estudada e definida. Isto é explicado pelo fato de que estas interações são de natureza complicada e existem limitações experimentais, como por exemplo, o difícil e em alguns casos impossível cultivo desses micro e macro-organismos marinhos em laboratório (HÖLLER et al., 2000; KOBAYASHI; KITAGAWA, 1994; KÖNIG et al., 2006; THAKUR; MÜLLER, 2004).

Isolados pertencentes a gêneros cosmopolitas, como Aspergillus, Penicillium, Alternaria e Cladosporium são fontes significativas de metabólitos secundários produzidos por fungos derivados de ambientes marinhos. Espécies pertencentes a esses gêneros são rotineiramente isoladas da superfície, tecidos internos e cavidades de algas, esponjas, ascídias e outros invertebrados marinhos. Em alguns casos, como o da esponja Aplysina aerophoba, a biomassa do organismo é composta por até $40 \%$ de micro-organismos. Até o momento, mais de 75 metabólitos de 25 espécies de fungos associados a esponjas foram descritos. Alguns desses metabólitos apresentam propriedades biológicas e estruturas únicas, enquanto outros se relacionam a metabólitos produzidos por fungos terrestres (GESNER et al., 2005; PROKSCH et al., 2003; TAYLOR et al., 2007; THAKUR; MÜLLER, 2004). König et al. (2006) relataram a ocorrência de representantes dos gêneros Gymnascella, Trichoderma, Phoma, Acremonium, Fusarium, Humicola, Cochliobolus e Curvularia associados a invertebrados marinhos como esponjas e cnidários, sendo estes considerados facultativos por ocorrerem também em ambientes terrestres. Muitos destes fungos, entretanto, se desenvolvem melhor em água do mar e parecem ter se adaptado ao ambiente marinho. Saffo et al. (1982) reportaram a presença de fungos do gênero Nephromyces no saco renal de seis espécies de ascídias. Estes haviam sido praticamente ignorados em outros estudos realizados até então, e os autores chamam atenção para um possível papel dos fungos no metabolismo das ascídias, embora este ainda seja desconhecido. 
Em um estudo recente realizado pelo nosso grupo de pesquisa (MENEZES et al., 2010) foi reportado uma grande diversidade de fungos pertencentes ao filo Ascomycota associada à diferentes amostras de invertebrados marinhos. A predominância desses fungos em ambientes aquáticos pode estar associada ao fácil cultivo e recuperação e à presença de esporos com apêndices, os quais facilitam a flutuabilidade na água e aderência ao substrato (PRASANNARAI; SRIDHAR, 2001).

Os oceanos nos têm revelado numerosos compostos e drogas promissoras, entretanto o desenvolvimento de drogas e compostos de aplicação real tem sido muito lento, devido às baixíssimas concentrações destes compostos nos organismos marinhos onde eles são encontrados. Estudos mostram que vários compostos bioativos produzidos por esponjas, por exemplo, são extremamente semelhantes, senão iguais, aos produzidos por micro-organismos conhecidos. Isso reforça a tese de que muitos dos compostos bioativos encontrados em organismos marinhos são produzidos, na realidade, por micro-organismos que habitam a superfície ou o interior dos mesmos, tornando necessária a realização de estudos mais detalhados sobre o papel dos micro-organismos simbiontes em esponjas, tunicados e outros organismos marinhos ricos em compostos bioativos. O sucesso no cultivo dos microorganismos associados é de extrema importância, nos provendo com uma fonte abundante e econômica dos compostos de interesse, amenizando assim o problema da baixa concentração de compostos encontrados nos invertebrados (PROKSCH et al., 2003; TAYLOR et al., 2007; THAKUR; MÜLLER, 2004; YOUSSEF, 2006), o que gera a necessidade de coleta massiva destes organismos no ambiente marinho. A fauna marinha brasileira permanece praticamente inexplorada na busca por novos produtos biologicamente ativos naturais (BERLINCK et al., 2004).

\subsection{Lipases: propriedades, produção e aplicaç̃̃es}

Lipases são enzimas hidrolíticas que agem em meios orgânico-aquosos, catalisando a clivagem de ligações do tipo éster em triglicerídeos, produzindo glicerol e ácidos graxos livres. Entretanto, em meios com pouca disponibilidade de água, as lipases têm a capacidade de catalisar reações de esterificação, interesterificação e transesterificação de glicerídeos e fosfoglicerídeos, bem como de uma variedade de ligações do tipo éster não glicerídicas, sendo assim biocatalisadores bastante versáteis. As características únicas das lipases incluem a especificidade de substrato, estereoespecificidade, regioespecificidade e a habilidade de 
catalisar reações heterogêneas na interface de sistemas solúveis e insolúveis em água (CAVALCANTI et al., 2005; CHOI; HWANG; KIM, 2003; FERRER et al., 2000; HOUDE; KADEMI; LEBLANC, 2004; JOSEPH et al., 2007; MAIA et al., 1999; SAVITHA et al., 2007).

Fungos filamentosos terrestres, especialmente os pertencentes aos gêneros Rhizopus, Mucor, Geotrichum, Aspergillus, Fusarium e Penicillium, são amplamente utilizados como fonte de lipases (FERRER et al., 2000; SAVITHA et al., 2007). Entre os micro-organismos derivados de ambiente marinho a levedura Candida antarctica destaca-se como uma importante fonte de lipases para biocatálise em aplicações industriais (DE MARÍA et al., 2005; SHIVAJI; PRASAD, 2009). No entanto ainda são as bactérias os maiores alvos de prospecção de lipases em ambiente marinho (BAHARUM; BENG; MOKHTAR, 2010). As lipases fúngicas são preferidas por serem geralmente excretadas no meio extracelular, o que facilita a sua extração dos meios de cultivo, além de apresentarem maior estabilidade a variações de temperatura e pH e de serem ativas em solventes orgânicos (MAIA et al., 1999; SAXENA et al., 1999).

A demanda por enzimas industriais, particularmente as de origem microbiana, tem crescido incessantemente devido as suas aplicações em uma vasta gama de processos. Enzimas como proteases e amilases dominaram o mercado por apresentarem atividades hidrolíticas em proteínas e carboidratos. Entretanto, com a descoberta do potencial biocatalítico das lipases microbianas nas últimas duas décadas, estas enzimas têm se tornado um grande foco de estudos e utilização em reações químicas diversas. As lipases utilizadas industrialmente são geralmente pertencentes a uma classe especial de esterases que agem em gorduras e óleos, e os hidrolisam primariamente em glicerídeos e ácidos graxos, para então catalisar a hidrólise total em glicerol e ácidos graxos (CAVALCANTI et al., 2005; SAXENA et al., 1999).

Substratos típicos para a produção de lipases são: óleo vegetal, gordura de origem animal, óleo de peixe, azeite de oliva, gordura do leite e alguns triacilglicerídeos sintéticos como a trioleína. Entre as características desejáveis que as lipases comerciais devem apresentar estão a tolerância a pH alcalino e a termoestabilidade. A maioria das lipases reportadas até o momento são ativas em pH neutro (SAVITHA et al., 2007).

São várias as aplicações das lipases em diversos setores industriais, incluindo: a) indústria alimentícia e de bebidas, onde são aplicadas para melhorar o sabor, aroma e 
aparência de alimentos, prolongar a conservação e até mesmo reduzir o teor de gorduras; b) indústria química e farmacêutica, onde atuam como catalisadores de reações para obtenção de compostos e lipídeos específicos, na síntese de surfactantes, além da utilização como auxiliar em medicamentos para dietas; c) indústrias papeleiras e de couros, onde são utilizadas como catalisadores de reações de hidrólise; d) indústria de produtos de limpeza, onde atuam como coadjuvantes em detergentes e sabões em pó; e e) indústria de cosméticos, onde são utilizadas como emulsificante e agente umidificante (CAVALCANTI et al., 2005; CHOI; HWANG; KIM, 2003; FERRER et al., 2000; HASAN; SHAH; HAMEED, 2006; HOUDE; KADEMI; LEBLANC, 2004; JAEGER; EGGERT, 2002; JAEGER; REETZ, 1998; JOSEPH et al., 2007; MAIA et al., 1999; DE MARÍA et al., 2005; PASTORE; DA COSTA; KOBLITZ, 2003; RESEARCHERS [...], 1987; SAVITHA et al., 2007; SAXENA et al., 1999; SCHMID; VERGER, 1998; SEITZ，1974; SHARMA; CHISTI; BANERJEE，2001; WANDREY; LIESE; KIHUMBU, 2000).

Uma aplicação das lipases que tem chamado atenção e envolvido grandes esforços em pesquisas é a produção de biocombustíveis. O processo utilizando lipases produz biodiesel diretamente, a partir da transesterificação dos ácidos graxos livres presentes em resíduos oleosos e óleos reciclados. Isto é particularmente interessante uma vez que o custo do material bruto contribui para $88 \%$ do custo de produção com óleos vegetais, que tem alto valor de mercado. O emprego destas enzimas tem as vantagens de não causar saponificação e corrosão, problemas comuns do processo tradicional catalisado por bases ou ácidos; contribuir para processos mais seguros e ecologicamente corretos; facilitar a separação do subproduto, glicerol; e diminuir o consumo de energia no processo. A principal desvantagem é o custo da enzima. Porém, esta pode ser imobilizada e reciclada e/ou produzida in-situ para contornar o problema (BISEN et al., 2010; PROSKOVÁ et al., 2010; SANDOVAL et al., 2009).

Sandoval et al. (2009) encontraram um isolado de Yarrowia lipolytica que produziu lipase com atividade comparável a enzimas comerciais utilizadas para produzir biodiesel a partir de resíduos oleosos. Nelson, Foglia e Marmer (1996) demonstraram que lipases de Mucor miehei e Candida antarctica podem ser empregadas na produção de biodiesel a partir de óleos vegetais, gordura animal e óleo de cozinha usado. Alves et al. (2006) utilizaram Aspergillus orizae geneticamente modificado com gene de lipase de Candida antarctica, empregado na transesterificação de óleo de babaçu com sucesso. A enzima imobilizada pôde ser reaproveitada em vários ciclos de produção mantendo sua atividade. De Oliveira et al. 
(2009) relataram a produção de lipase por Fusarium sp. com potencial para aplicação na produção de biodiesel. Lipases dos fungos Candida antarctica, Rhizomucor miehei, Thermomyces lanuginosa, Rhizopus oryzae, Candida rugosa e Candida cilindracea estão presentes em preparações comercializadas e empregadas na produção de biodiesel a partir de diferentes óleos e gorduras (BISEN et al., 2010; COSTA NETO, 2002; PROSKOVÁ et al., 2010; RODRIGUES, 2009).

Outra importante aplicação para as lipases de origem microbiana, e mais especificamente as de origem fúngica, está relacionada com a biodegradação de hidrocarbonetos, visto que estes, devido à dominância de produtos derivados de petróleo no mercado, constituem importantes fontes de contaminação de ecossistemas (ADENKUNLE; ADEBAMBO, 2007). Os aparentemente inevitáveis derramamentos de petróleo decorrentes de operações de rotina e acidentes mantêm atualmente um grande esforço nas pesquisas nessa área. A atenção tem sido voltada para os ecossistemas marinhos, pois estes são os maiores receptores de hidrocarbonetos poluentes (ATLAS, 1981; LEAHY; COLWELL, 1990).

A transformação de hidrocarbonetos por fungos marinhos é uma área de destaque uma vez que estes organismos são relativamente comuns e já demonstraram potencial para tal aplicação (MacGILLIVRAY; SHIARIS, 1993). Os hidrocarbonetos de petróleo são mencionados como substratos em potencial para a produção microbiana de enzimas comerciais importantes e outros metabólitos secundários (MARTINS; KALIL; COSTA, 2008).

De acordo com Adekunle e Adebambo (2007) e Lemos et al. (2002) os fungos são mais eficientes na degradação de petróleo quando comparados com as bactérias utilizadas em técnicas tradicionais de biorremediação, por se ramificarem rapidamente pelo substrato e secretarem grandes quantidades de enzimas extracelulares. Além disso, em alguns casos os fungos são mais bem adaptados para viverem em condições de estresse como as encontradas em ambientes marinhos. Adekunle e Adebambo (2007) também reportam que estudos realizados com fungos patógenos de sementes oleaginosas mostraram que estes produzem certas lipases que lhes confere a capacidade de utilizar hidrocarbonetos presentes no petróleo. Entre os fungos mais comumente isolados de ambientes marinhos contaminados com hidrocarbonetos estão alguns representantes dos gêneros Aureobasidium, Candida, Rhodotorula, Sporobolomyces, Aspergillus e Penicillium (LEAHY; COLWELL, 1990). 
Embora muitos dos fungos identificados como degradadores de hidrocarbonetos encontrados em ambientes marinhos sejam na verdade fungos terrestres chamados de "geofungos", sendo representantes de Penicillium e Aspergillus os mais comuns, algumas espécies obrigatoriamente marinhas capazes de degradar hidrocarbonetos são conhecidas. Entre estas temos representantes dos gêneros Corollospora, Varicosporina, Lulworthia, Dendryphiella, entre outras (LEMOS et al., 2002; KIRK; GORDON, 1988).

Neste contexto, a proposta de isolamento e seleção de fungos derivados de ambiente marinho produtores de lipases, visando sua aplicação em processos de degradação de hidrocarbonetos resultantes de derramamento acidental de petróleo nos oceanos, é estrategicamente muito interessante, uma vez que estes organismos já estão adaptados às condições destes ambientes (BAHARUM; BENG; MOKHTAR, 2010).

\subsection{Biosurfactantes e agentes emulsificantes}

Biosurfactantes são agentes de superfície que apresentam atividade emulsificante, deemulsificante, umidificante, espumante, dispersante, detergente e/ou solubilizante. Estes compostos têm sido extensivamente estudados, pois tem aplicação em diversos setores industriais (BOSCH et al., 1988; NERURKAR; HINGURAO; SUTHAR, 2009; PARASZKIEWICZ et al., 2002). São um grupo estruturalmente diverso, que inclui glicolipídios, lipopeptídios, fosfolipídios, ácidos graxos e polímeros (LUNA-VELASCO et al., 2007). Podem ser divididos em moléculas de baixa massa, que diminuem as tensões de superfície e interface, e polímeros de alta massa molecular, que são mais efícientes na estabilização de emulsões (PARASZKIEWICZ et al., 2002).

Surfactantes e emulsificantes de origem biológica podem ser tão eficientes quanto os sintéticos e apresentam estruturas químicas e propriedades físicas incomuns, além de comumente apresentarem melhor biodegradabilidade, seletividade, biocompatibilidade, baixa toxicidade e serem efetivos em extremos de $\mathrm{pH}$, temperatura e salinidade (LUNA-VELASCO et al., 2007). São freqüentemente encontrados no meio extracelular ou então integrados a superfície das células (BOSCH et al., 1988). Produzidos por micro-organismos específicos, principalmente bactérias e leveduras, os biosurfactantes podem aumentar a utilização e/ou detoxificação de substratos hidrofóbicos (PARASZKIEWICZ et al., 2002). A natureza do micro-organismo, o substrato e as condições de cultivo determinam a composição dos biosurfactantes, que é variável e confere propriedades físico-químicas específicas. Todas estas 
propriedades lhes conferem uma vasta gama de aplicações nas indústrias alimentícia, de cosméticos, farmacêutica e petrolífera, além da biorremediação de poluentes (LUNAVELASCO et al., 2007).

A biodegradação e/ou biotransformação de substratos imiscíveis em meios aquosos como hidrocarbonetos e triacilgliceróis é limitada pela pequena disponibilidade destes compostos às células (PARASZKIEWICZ et al., 2002). O mesmo acontece em solos contaminados com hidrocarbonetos (WILLUMSEN; KARLSON, 1997). A maioria dos micro-organismos que são capazes de assimilar hidrocarbonetos também são capazes de emulsificar esses hidrocarbonetos durante a etapa de degradação do substrato (CIRIGLIANO; CARMAN, 1984; LUNA-VELASCO et al., 2007), disponibilizando estas moléculas para o metabolismo da célula (BOSCH et al., 1988).

Apesar da maioria dos agentes emulsificantes extracelulares terem sido encontrados em culturas de bactérias e leveduras capazes de degradar hidrocarbonetos (CIRIGLIANO; CARMAN, 1984), já foi reportada a produção de alguns destes compostos anfipáticos em meio contendo carboidratos como a glicose e outros açúcares, óleos, resíduos agrícolas ou etanol como fonte de carbono (BOSCH et al., 1988; LUNA-VELASCO et al., 2007; PARASZKIEWICZ et al., 2002).

Existem poucos trabalhos a respeito da produção de surfactantes por fungos filamentosos (LUNA-VELASCO et al., 2007). Entre estes foi reportada a espécie Curvularia lunata, patógeno de plantas e do homem, utilizado pela indústria farmacêutica na produção de hidrocortisona. Este fungo é capaz de produzir um agente emulsificante de estrutura protéicopolissacarídica em meio líquido contendo glicose como fonte de carbono (PARASZKIEWICZ et al., 2002). Também foram reportados fungos degradadores de poluentes orgânicos, como espécies de Penicillium isoladas de locais contaminados por hidrocarbonetos e que são capazes de produzir bioemulsificantes em meio suplementado com fenantreno (LUNA-VELASCO et al., 2007). Colin, Baigorí e Pera (2010) reportaram a produção de um bioemulsificante por Aspergillus niger em meio contendo sacarose como fonte de carbono.

Micro-organismos marinhos produzem bioemulsificantes com algumas características incomuns como tolerância ao $\mathrm{pH}(3-12)$, temperatura $\left(20-100^{\circ} \mathrm{C}\right)$ e salinidade $(0,5-2,0 \%)$. O número de estudos envolvendo emulsificantes de origem marinha e/ou ativos em meio salino é reduzido, mas estes têm chamado atenção, particularmente para aplicação na bioremediação 
de derramamentos de petróleo. A maioria avalia bactérias e leveduras, como Acinetobacter spp., Bacillus spp., Halomonas sp. e Yarrowia lipolytica (MANEERAT, 2005; NERURKAR; HINGURAO; SUTHAR, 2009). Sarubbo, De Luna e Campos-Takaki (2006) obtiveram um isolado de Candida glabrata de sedimentos de mangue da cidade de Rio Formoso, Pernambuco que foi capaz de produzir um agente emulsificante com atividade de emulsificação estável de $75 \%$ em óleo de semente de algodão. A atividade manteve-se praticamente inalterada em $\mathrm{pH} 2-12$, temperatura de 4 a $80{ }^{\circ} \mathrm{C}$ e salinidade de até $10 \%$.

Bonugli-Santos et al. (2009) e Passarini et al. (2010) estudaram fungos filamentosos associados a cnidários marinhos que se mostraram capazes de degradar hidrocarbonetos policíclicos aromáticos (HPAs). Entretando, Bonugli-Santos et al. (2009) verificaram que estes não apresentaram bons resultados de redução de tensão superficial nem de emulsificação. Vasconcellos (2006) também registrou resultados semelhantes em estudo com bactérias isoladas de petróleo. Os resultados sugerem que novos estudos devem ser realizados acerca dos mecanismos de produção e ação de surfactantes e agentes emulsificantes. A produção destes compostos poderia ser um mecanismo de sobrevivência - o micro-organismo que não consegue utilizar o substrato disponível produziria exopolímeros para disponibilizá-lo mais facilmente para consumo. Além disso, pode ocorrer interdependência metabólica: enquanto alguns micro-organismos do meio emulsificam e solubilizam os compostos, outros os degradam (BONUGLI-SANTOS et al., 2009).

\subsection{Taxonomia de fungos filamentosos}

A identificação e classificação adequada dos fungos é crítica para o estudo de compostos naturais. Sem a identificação e preservação adequada dos isolados, investigações químicas de fungos tornam-se difíceis, senão impossíveis de serem reproduzidas (BUGNI; IRELAND, 2004; DAS; LAYLA; KHAN, 2006).

Apesar da identificação primária dos fungos ser historicamente realizada com base em caracteres morfológicos, os micologistas atualmente empregam diferentes técnicas para auxiliar na taxonomia e sistemática. A morfologia ainda tem um importante papel na taxonomia, porém o uso de dados moleculares tem se tornado mais comum (BUGNI; IRELAND, 2004).

Estudos morfológicos que utilizam identificação baseada em caracteres de reprodução (taxonomia convencional) podem apresentar dificuldades para serem realizados devido a 
vários motivos: a inabilidade de alguns fungos de crescer e esporular em meios de cultura; diferentes taxas de esporulação; presença de formas desconhecidas do ciclo de vida e limitações na distinção de espécies com morfologias semelhantes (PANG; MITCHELL, 2005). A maioria da biomassa de fungos marinhos consiste de hifas vegetativas e conídios que não podem ser identificados por microscopia tradicional (DAS; LAYLA; KHAN, 2006). Entretanto, as fases sexuadas e assexuadas são precisamente a base da taxonomia e nomenclatura dos fungos (GUARRO; GENÉ; STCHIGEL, 1999).

As técnicas moleculares caracterizam os ácidos nucléicos presentes em todos os estágios do ciclo de vida do fungo, e desta forma não estão passíveis a muitos dos problemas associados com as técnicas baseadas em análises macro e microscópicas (DAS; LAYLA; KHAN, 2006). Uma das técnicas moleculares mais empregadas na identificação e no estudo filogenético de fungos é a utilização do DNA do operon ribossomal (Figura 1). Os genes DNAr $18 \mathrm{~S}$ e $28 \mathrm{~S}$ e as regiões ITS (Internal Transcribed Spacer) e IGS (Internal Gene Spacer) estão entre as regiões do operon ribossomal mais estudadas em fungos. Visto que as regiões ITS são consideravelmente divergentes entre si e variam entre as espécies de um mesmo gênero, as mesmas têm grande utilidade na taxonomia. Apesar de a região ITS ser comumente utilizada como ferramenta taxonômica, a região IGS é a mais divergente, podendo ser útil para diferenciar espécies extremamente relacionadas que possuem regiões ITS idênticas ou quase idênticas (BUGNI; IRELAND, 2004). Várias publicações relatam a aplicação de regiões de DNA do operon ribossomal na avaliação da diversidade e caracterização de comunidades, identificação, prospecção e tipagem, bem como para o estabelecimento de relações filogenéticas (ABARCA et al., 2004; ABLITZ et al., 2004; LOBUGLIO; TAYLOR, 1995; MARSHALL et al., 2003; PEINTNER et al., 2003; SCHABEREITER-GURTNER et al., 2001; STERFLINGER; PRILLENGER, 2001; SUTAR et al., 2004).

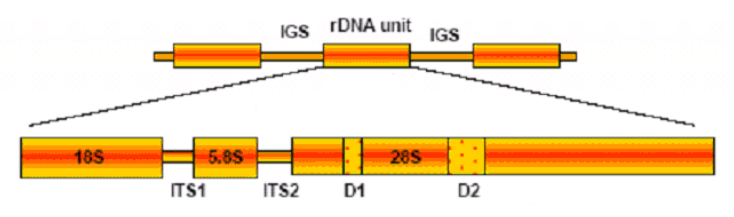

Figura 1. Esquema representando o operon ribossomal dos fungos. 
O presente trabalho teve como objetivos o isolamento de fungos filamentosos a partir de amostras de água do mar e de macro-organismos marinhos; a seleção de fungos lipolíticos e avaliação da produção de lipases; o estudo da atividade de emulsificação dos isolados que apresentaram melhores resultados de atividade lipolítica e a caracterização taxonômica dos isolados que apresentaram potencial para utilização em processos biotecnológicos. 


\section{MATERIAL E MÉTODOS}

\subsection{Isolados estudados}

Os fungos utilizadas no presente projeto foram recuperados de amostras de água do mar e de macro-organismos marinhos provenientes de duas coletas realizadas em períodos e pontos distintos da região de São Sebastião/Ilhabela, litoral norte do Estado de São Paulo, no âmbito do projeto Temático Fapesp 05/60175-2. As amostras foram processadas no Centro de Biologia Marinha da Universidade de São Paulo (CEBIMAR/USP) logo após as coletas.

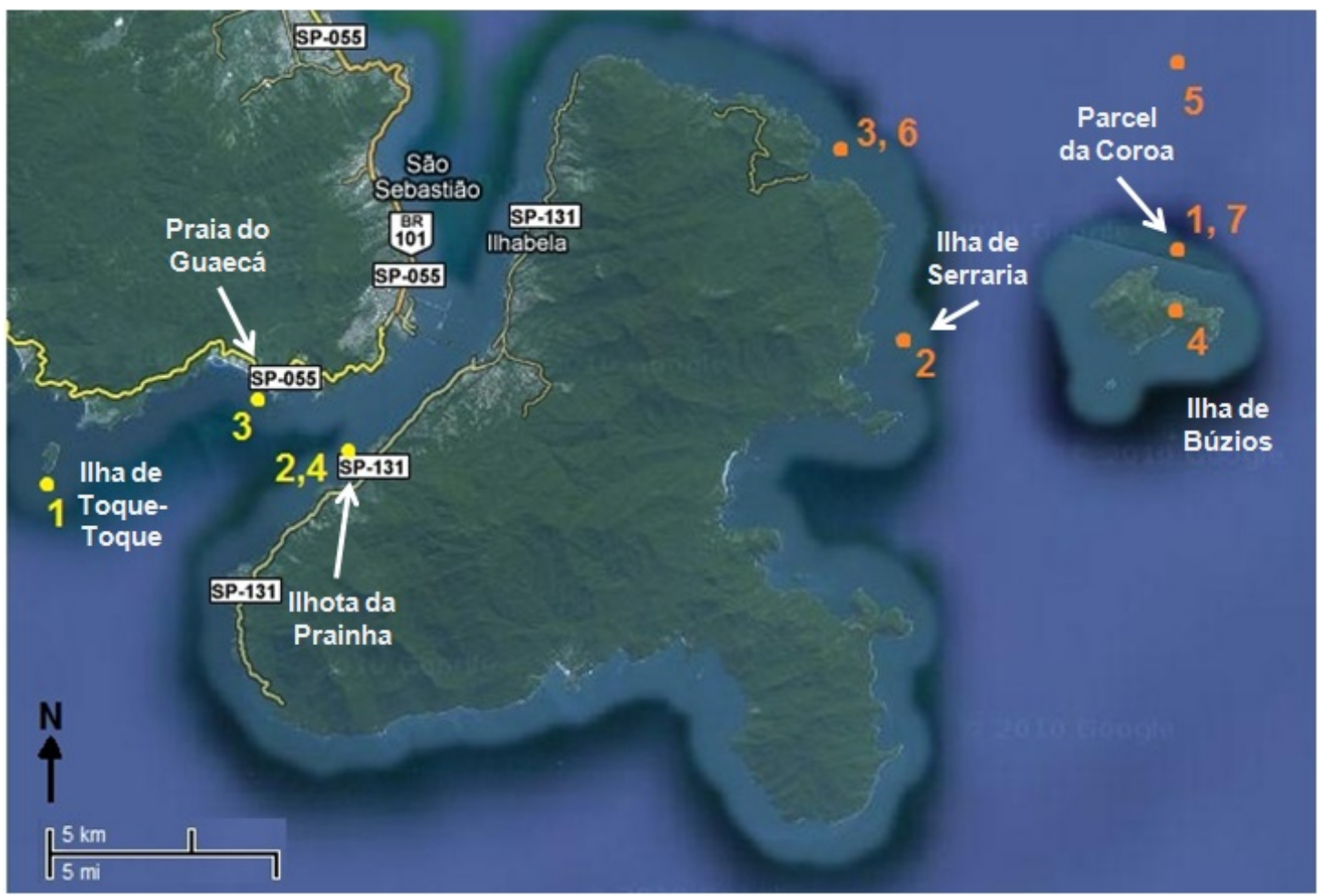

Figura 2. Pontos de coleta na região de São Sebastião/Ilhabela - SP. Primeira coleta em amarelo, segunda coleta em laranja.

Tabela 1 - Primeira coleta realizada no período de oito a 11 de janeiro de 2007.

\begin{tabular}{|c|c|c|}
\hline Amostra & & (Ponto de coleta) Local \\
\hline Amphimedon viridis & Esponja & (3) Praia do Guaecá - $23^{\circ} 49 \mathrm{~S} / 45^{\circ} 25 \mathrm{~W}$ \\
\hline Dragmacidon reticulata & Esponja & (1) Ilha de Toque-Toque $-23^{\circ} 51 \mathrm{~S} / 45^{\circ} 31 \mathrm{~W}$ \\
\hline Mycale laxissima & Esponja & (2) Ilhota da Prainha $-23^{\circ} 51 \mathrm{~S} / 45^{\circ} 24 \mathrm{~W}$ \\
\hline Didemnum sp. & Ascídia & (4) Ilhota da Prainha $-23^{\circ} 51 \mathrm{~S} / 45^{\circ} 24 \mathrm{~W}$ \\
\hline
\end{tabular}


O processamento da amostra, bem como isolamento dos fungos filamentosos foi realizado de acordo com Menezes et al. (2010). De um total de 257 isolados obtidos pelos autores, 142 foram utilizados no presente projeto, sendo estes os representantes de grupos taxonômicos distintos selecionados após análise de fingerprinting genético gerado por restrição enzimática (método de ARDRA) (MENEZES et al., 2010). Os repiques destas culturas foram feitos em meio Ágar-malte 2 (MA2 - composição em g/L: extrato de malte, 20,0; ágar, 15,0) acrescido de 3\% de $\mathrm{NaCl}$.

\subsubsection{Isolamento}

As amostras de invertebrados e da alga obtidas na segunda coleta foram lavadas com água do mar esterilizada. Fragmentos dos espécimes foram inoculados em placas de Petri contendo Meio de Tubaki (TM - composição em g/L: glicose, 3,0; extrato de levedura, 0,5; peptona, 1,0; $\mathrm{K}_{2} \mathrm{HPO}_{4}, 1,0 ; \mathrm{MgSO}_{4} .7 \mathrm{H}_{2} \mathrm{O}, 0,5 ; \mathrm{FeSO}_{4} .7 \mathrm{H}_{2} \mathrm{O}, 0,01$; ágar, 15,0) preparado com água do mar artificial (ASW - composição em g/L: KBr, 0,1; $\mathrm{NaCl}, 23,48 ; \mathrm{MgCl}_{2} \cdot 6 \mathrm{H}_{2} \mathrm{O}$, 10,$61 ; \mathrm{KCl}, 0,66 ; \mathrm{SrCl}_{2} \cdot 6 \mathrm{H}_{2} \mathrm{O}, 0,04 ; \mathrm{Na}_{2} \mathrm{SO}_{4}, 3,92 ; \mathrm{NaHCO}_{3}, 0,19 ; \mathrm{H}_{3} \mathrm{BO}_{4}, 0,03 ; \mathrm{CaCl}_{2} .2 \mathrm{H}_{2} \mathrm{O}$, 1,47). A amostra de água do mar foi semeada diretamente em placas de Petri contendo o mesmo meio. As placas foram mantidas em incubadora a $25{ }^{\circ} \mathrm{C}$ por $20-30$ dias e o crescimento dos fungos filamentosos foi acompanhado a cada dois dias para o isolamento e purificação.

Tabela 2 - Segunda coleta realizada no período de dois a cinco de dezembro de 2008.

\begin{tabular}{|c|c|c|}
\hline Amostra & & (Ponto de coleta) Local \\
\hline Água do mar & & 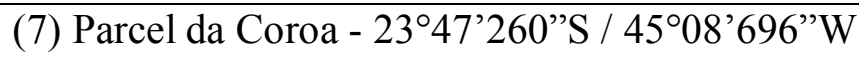 \\
\hline Axinella corrugata & Esponja & (1) Parcel da coroa - $23^{\circ} 47^{\prime} 260^{\prime \prime} \mathrm{S} / 45^{\circ} 08^{\prime} 696^{\prime \prime} \mathrm{W}$ \\
\hline Chelonaplysilla erecta & Esponja & (2) Ilha de Serraria $-23^{\circ} 48^{\prime} 39^{\prime \prime} \mathrm{S} / 45^{\circ} 13^{\prime} 45^{\prime \prime} \mathrm{W}$ \\
\hline Codium intertextum & Alga & (6) $23^{\circ} 45^{\prime} 32^{\prime \prime} \mathrm{S} / 45^{\circ} 15^{\prime} 08^{\prime \prime} \mathrm{W}$ \\
\hline Echinaster brasiliensis & Estrela & (4) Ilha de Búzios $-23^{\circ} 48^{\prime} 862^{\prime} \mathrm{S} / 45^{\circ} 08^{\prime} 901^{\prime} \mathrm{W}$ \\
\hline Estrela NI & Estrela & (5) Ilha de Búzios - 2347’371’S / 4508’771”W \\
\hline Petromica citrina & Esponja & (3) $23^{\circ} 45^{\prime} 32^{\prime \prime} \mathrm{S} / 45^{\circ} 15^{\prime} 8^{\prime \prime} \mathrm{W}$ \\
\hline
\end{tabular}


Os isolados obtidos tanto na primeira quanto na segunda coleta foram preservados na coleção de pesquisa associada à Coleção Brasileira de Micro-organismos de Ambiente e Indústria (CPQBA/UNICAMP) utilizando dois métodos distintos: Castellani (preservação em água esterilizada a $4{ }^{\circ} \mathrm{C}$ ) e ultracongelamento (criopreservação em $10 \%$ de glicerol a $-80{ }^{\circ} \mathrm{C}$ ). Os fungos filamentosos derivados da segunda coleta foram juntamente com os fungos selecionados na primeira coleta avaliados quanto à atividade lipolítica.

\subsection{Avaliação e quantificação da produção de lipases}

Para avaliar a produção de lipases e quantificar a atividade lipolítica dos isolados selecionadas foram utilizadas as metodologias descritas por Savitha et al. (2007).

\subsubsection{High throughput screening-HTS de lipase}

Esta metodologia envolve a medida de fluorescência causada pela interação da rodamina $\mathrm{B}$ com os ácidos graxos liberados pela hidrólise enzimática do azeite de oliva (KOUKER; JAEGER, 1987).

Os fungos da primeira coleta foram reativados em meio líquido contendo $20,0 \mathrm{~g} / \mathrm{L}$ de extrato de malte acrescido de 30,0 $\mathrm{g} / \mathrm{L}$ de $\mathrm{NaCl}$, enquanto os isolados da segunda coleta foram reativados em meio TM/ASW líquido (sem adição de ágar). Após crescimento por $72 \mathrm{~h}$ a 25 ${ }^{\circ} \mathrm{C}$ os isolados foram transferidos para placas deepwell de 96 poços, e inoculados com o auxílio de um replicador em placas de Petri. Esta técnica é conhecida como High Throughput Screening (HTS), e foi adaptada de Kouker e Jaeger (1987) para placas de 96 poços. Os inóculos foram colocados em pocinhos alternados nas placas deepwell para evitar a sobreposição de colônias, uma vez que os fungos avaliados possuem velocidades de crescimento distintas.

Para este teste foi utilizado o meio TM modificado (sem glicose, acrescido de $3 \%$ de $\mathrm{NaCl}$ e preparado com água destilada). $\mathrm{O}$ meio foi esterilizado por autoclavagem e resfriado a $60{ }^{\circ} \mathrm{C}$. Foram então adicionados $31,25 \mathrm{ml} / \mathrm{L}$ de óleo de oliva purificado em coluna de alumina para remoção dos ácidos graxos livres como descrito por Jensen et al. (1966), $10 \mathrm{ml} / \mathrm{L}$ de solução de rodamina B - álcool etílico 0,001\% (v/v) com agitação intensa (liquidificador esterilizado com luz UV) durante um minuto para formar uma emulsão. Para reduzir a 
quantidade de espuma o meio descansou por dez minutos antes de ser vertido em placas de Petri. Devido à presença da rodamina $\mathrm{B}$, também conhecida como rodamina 610 , basic Violet 10 ou C.I. 45170 , as placas apresentaram coloração rosa característica.

Após $48 \mathrm{~h}$ de incubação a $25{ }^{\circ} \mathrm{C}$ o resultado positivo para produção de lipase foi observado por meio de irradiação das placas com luz UV 366nm. As colônias positivas apresentaram fluorescência amarelo-alaranjado enquanto as negativas acumularam rodamina B (formaram colônias rosadas), mas não apresentam fluorescência.

Os isolados que apresentaram resultados positivos de produção de lipase no teste HTS foram avaliados individualmente nas mesmas condições para confirmação dos resultados.

\subsubsection{Confirmação da produção de lipase}

Os isolados selecionados por apresentarem resultados positivos no experimento de High Tthroughput Screening foram reativados em meio MA2 $+3 \% \mathrm{NaCl}$ (primeira coleta) e TM/ASW (segunda coleta). Cilindros de cinco $\mathrm{mm}$ de diâmetro do meio de cultura + fungo foram inoculados em placas de Petri contendo meio TM modificado + azeite de oliva / rodamina $\mathrm{B}$ (mesmo meio utilizado no item 4.2.1). Após incubação por $48 \mathrm{~h}$ a $25{ }^{\circ} \mathrm{C}$ o resultado foi visualizado por meio de irradiação das placas com luz UV 366nm, sendo consideradas positivas as culturas que apresentaram fluorescência amarelo-alaranjado.

\subsubsection{Quantificação da atividade lipolítica}

Os isolados selecionados por apresentarem resultados positivos de produção de lipase nos dois testes realizados foram submetidos aos experimentos de quantificação da atividade lipolítica em pH 6,0 e pH 8,0.

\subsubsection{Preparo do inóculo e condições de cultivo}

Após o crescimento dos fungos nos meios contendo ágar - rodamina $\mathrm{B}+$ óleo de oliva como fonte de carbono (item 3.2.1) por $48 \mathrm{~h}$, foram retirados dois cilindros de cinco $\mathrm{mm}$ em diâmetro da margem das colônias e transferidos para frascos de Erlenmeyer de $50 \mathrm{~mL}$ com 20 $\mathrm{mL}$ de meio contendo (g/L): $\mathrm{KH}_{2} \mathrm{PO}_{4}$. 7,0; $\mathrm{Na}_{2} \mathrm{HPO}_{4}, 2,0 ; \mathrm{MgSO}_{4} .7 \mathrm{H}_{2} \mathrm{O}, 1,5$; extrato de 
levedura, 1,$0 ; \mathrm{CaCl}_{2} .2 \mathrm{H}_{2} \mathrm{O}, 0,1 ; \mathrm{FeCl}_{2} .4 \mathrm{H}_{2} \mathrm{O}, 0,008 ; \mathrm{ZnSO}_{4} .7 \mathrm{H}_{2} \mathrm{O}, 0,0001$; tartarato de amônio dibásico, 1,5; pH 6,0. Como fonte de carbono foi adicionado ao meio óleo de oliva purificado $(1 \%, \mathrm{w} / \mathrm{v})$ e como controle a glicose $(1 \%, \mathrm{w} / \mathrm{v})$. As culturas foram incubadas durante cinco dias sob agitação de $150 \mathrm{rpm}$ a $28{ }^{\circ} \mathrm{C}$ e então filtradas com papel filtro. Os filtrados foram utilizados para a quantificação da atividade lipolítica.

\subsubsection{Quantificação da atividade lipolítica}

O substrato utilizado para quantificação da atividade lipolítica foi composto de duas soluções, A e B. A solução A foi preparada com $40 \mathrm{mg}$ de p-nitrofenil palmitato (pNPP) dissolvidos em $12 \mathrm{~mL}$ de isopropanol. A solução B foi composta de 0,1 g de goma arábica e 0,4 mL de Triton X-100 dissolvidos em $90 \mathrm{~mL}$ de água. O substrato foi preparado pelo gotejamento de um $\mathrm{mL}$ da solução $\mathrm{A}$ em $19 \mathrm{~mL}$ da solução $\mathrm{B}$, com agitação constante para formar uma emulsão estável por até duas horas. A solução teste foi preparada com $0,5 \mathrm{~mL}$ do substrato, $250 \mu \mathrm{L}$ de tampão, $50 \mu \mathrm{L}$ de enzima (o filtrado) e teve o volume completado para 1,5 $\mathrm{mL}$ com água destilada. O teste foi realizado em $\mathrm{pH} 6,0$ e $\mathrm{pH} \mathrm{8,0,} \mathrm{e} \mathrm{para} \mathrm{tanto} \mathrm{foram}$ utilizados dois tampões fosfato de sódio - ácido cítrico $100 \mathrm{mM}$ ajustados para os diferentes valores de $\mathrm{pH}$. Os controles foram preparados da mesma forma, porém sem a adição do substrato. Todos os testes foram realizados em triplicata. Os tubos foram incubados por 45 minutos a $40{ }^{\circ} \mathrm{C}$. Em seguida a atividade enzimática foi cessada com a adição de $100 \mu \mathrm{L}$ de isopropanol. A absorbância foi então medida a $410 \mathrm{~nm}$ em espectrofotômetro. O gráfico padrão foi construído com a utilização de p-nitrofenol $(0,4$ a $16,0 \mu$ moles $)$. A atividade foi expressa em U. Uma unidade de lipase (U) é definida como a quantidade de enzima que libera um $\mu \mathrm{mol}$ de p-nitrofenol por minuto sob as condições descritas (MAIA et al., 1999).

\subsection{Atividade emulsificante}

Os fungos cujos extratos brutos apresentaram atividade lipolítica elevada ( $U \geq 10,0$ em $\mathrm{pH} 8,0$ ) foram submetidos ao teste de emulsificação descrito por Willumsen e Karlson (1997) adaptado para as condições de cultivo dos micro-organismos em estudo.

Após crescimento em meio líquido (mesmo meio utilizado no item 3.2.3.1) durante cinco dias a $28{ }^{\circ} \mathrm{C}$ e $150 \mathrm{rpm}$ as culturas foram centrifugadas a $12000 \mathrm{rpm}$ por 30 minutos. Os 
sobrenadantes foram então avaliados quanto a sua capacidade de formar uma emulsão estável. Para tanto foram submetidos à agitação vigorosa (20 segundos em vortex e 20 segundos de agitação manual) em tubos contendo $3,5 \mathrm{~mL}$ dos extratos e 2,0 $\mathrm{mL}$ de azeite de oliva, óleo diesel ou n-hexadecano e mantidos em repouso. Os testes foram realizados em triplicata. Ensaios sem inóculo foram utilizados como controle e ensaios apenas com meio salino (sem azeite de oliva no meio de crescimento) como branco.

Duas horas após a agitação a altura das fases de emulsão foi medida. Um dia depois as medidas foram feitas novamente para verificar a estabilidade da emulsão. $O$ índice de emulsificação ou EI (emulsification índex) corresponde à razão entre a altura da camada de emulsão e altura total da fase oleosa. EI $=0$ indica que não houve emulsificação, e EI $=1$, $100 \%$ de emulsificação. Um produtor de emulsificante é considerado promissor se tiver EI $\geq$ 0,4 (40\% de emulsificação da fase oleosa) duas horas após agitação (BOSCH et al., 1988). A emulsão é definida como estável se o EI após 24 h corresponder a $50 \%$ ou mais do EI medido com duas horas.

\subsection{Caracterização taxonômica}

Os isolados que apresentaram atividade lipolítica significativa $(\mathrm{U} \geq 1,0 \mathrm{em} \mathrm{pH} \mathrm{8,0)}$ foram identificados e depositados na Coleção Brasileira de Micro-organismos de Ambiente e Indústria (CBMAI). Os fungos recuperados das amostras da primeira coleta foram previamente identificados com base na taxonomia molecular (seqüenciamento de gene do operon ribossomal e análise filogenética) de acordo com Menezes et al. (2010).

No presente trabalho os isolados selecionados foram submetidos a análise taxonômica convencional baseada em caracteres macro-morfológicos (diâmetro, coloração e aspecto das colônias, produção de pigmento difusível e presença de exsudado) e micro-morfológicos (tamanho, forma e ornamentação de esporos; tamanho e forma de fiálides e métulas; ramificação; presença e forma de macro-conídios, entre outros). Os dados observados foram comparados com a literatura pertinentes (DE HOOG et al., 2000; DOMSCH; GAMS; ANDERSON, 1980; KLICH; PITT, 1988; PITT, 1979; SAMSON; HOEKSTRA; FRISVAD, 2002). 


\section{RESULTADOS E DISCUSSÃO}

\subsection{Isolados estudados}

Dentre os 256 isolados obtidos na primeira coleta, 144 apresentaram ribotipos distintos no fingerprinting genético (ARDRA). Estes isolados foram caracterizados até o nível de gênero por Menezes et al. (2010). Segundo os autores os fungos filamentosos isolados estão distribuídos em 24 taxa distintos pertencentes aos filos Ascomycota, Zygomycota e Basidiomycota, alguns dos quais nunca foram reportados como associados a invertebrados marinhos (Pestalotiopsis, Xylaria, Botrysphaeria e Cunninghamella). Dos 144 fungos que apresentaram ribotipos distintos, 142 foram selecionados para a condução do presente estudo, sendo que 33 são derivados das amostras da esponja Amphimedon viridis (AV), 37 da esponja Dragmacidon reticulata (DR), 39 da ascídia Didemnum sp.(Dsp), 28 da esponja Mycale laxissima (ML) e cinco isolados provenientes de amostras não identificadas. Dois dos 142 isolados foram desconsiderados no presente estudo pois não puderam ser reativados, o que pode estar relacionado com os métodos de preservação empregados, que podem ter sido ineficientes para ambos.

A partir dos macro-organismos da segunda coleta foram obtidos 35 isolados de fungos filamentosos. Nesta etapa foi utilizada a metodologia de inoculação de fragmentos das amostras diretamente nas placas por ter sido esta a que apresentou melhores resultados no isolamento de fungos filamentosos derivados da primeira coleta. O meio escolhido foi o TM por ser um meio amplamente utilizado para isolamentos de micro-organismos associados a amostras marinhas e por ter sido um dos melhores para o isolamento de fungos na primeira coleta (MENEZES et al., 2010).

Dos 35 isolados obtidos na segunda coleta, seis são derivados da esponja Axinella corrugata (AC), um de Chelonaplysilla erecta (CE) e quatro de Petromica citrina (PC); dois da estrela Echinaster brasiliensis (EB) e cinco da estrela não identificada (EST*); três da alga Codium intertextum (CI) e 14 da amostra de água (H2O) (Figura 3). Treze isolados acabaram sendo desconsiderados por não poderem ser reativados, indicando que os métodos de preservação utilizados podem não ter sido eficientes para estes isolados. 


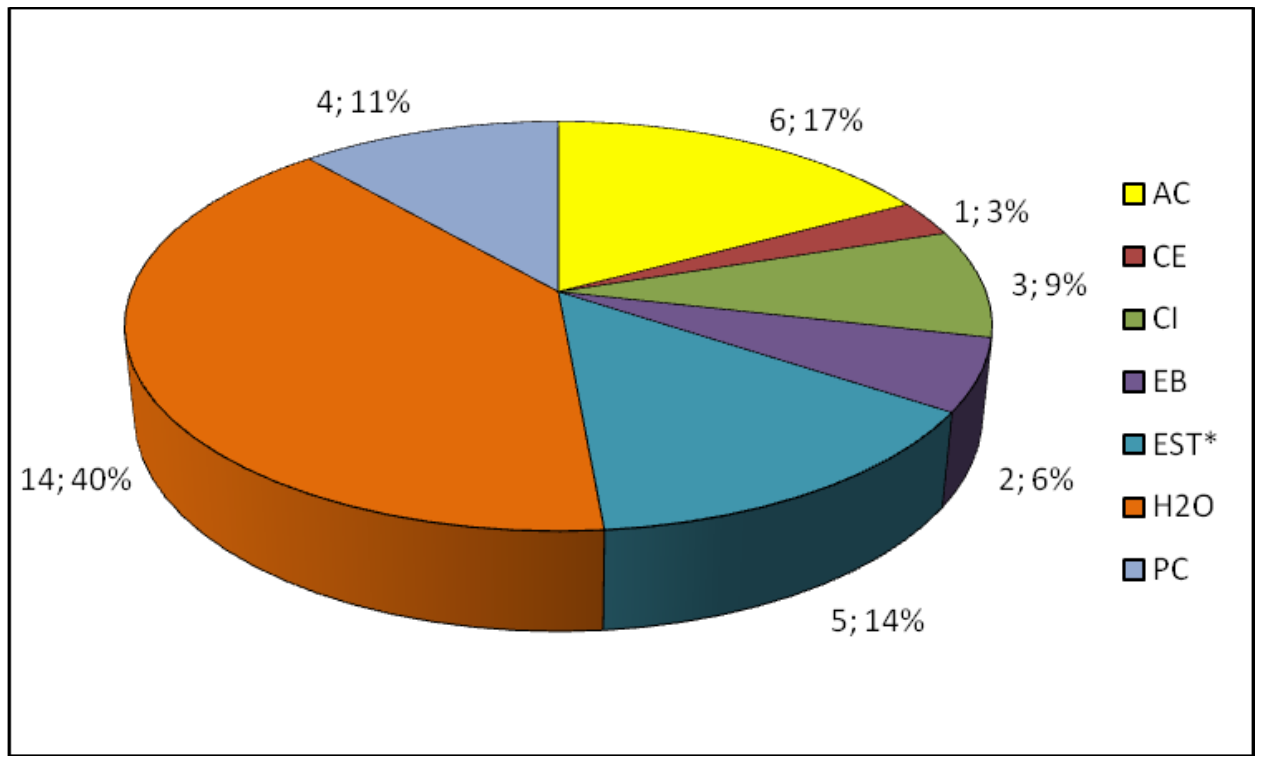

Figura 3. Fungos filamentosos obtidos na segunda coleta e as amostras de macro-organismos marinhos de onde os mesmos foram isolados. AC - Axinella corrugata; CE Chelonaplysilla erecta; CI - Codium intertextum; EB - Echinaster brasiliensis; EST* estrela não identificada; $\mathrm{H} 2 \mathrm{O}$ - amostra de água e PC - Petromica citrina.

\subsection{Avaliação e quantificação da produção de lipases}

\subsubsection{High throughput screening-HTS de lipase}

Entre os 162 fungos filamentosos submetidos ao experimento de triagem de alto desempenho (Figura 4), 72 (44\%) apresentaram resultado positivo para lípase, sendo 62 derivados da primeira coleta e 10 da segunda coleta (Figura 5).

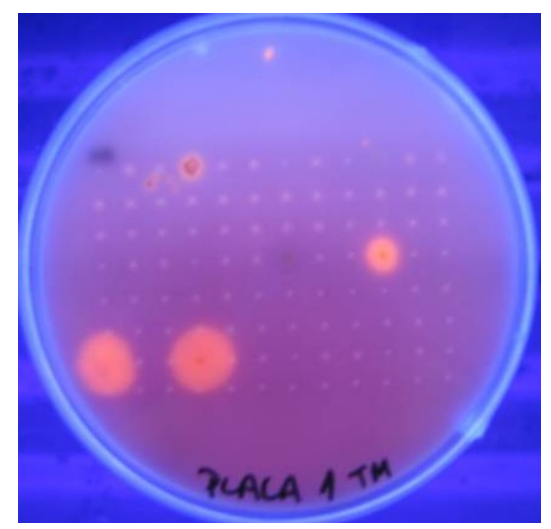

Figura 4. HTS utilizado para seleção de fungos filamentosos lipolíticos derivados de invertebrados marinhos após 48 horas de incubação a $28^{\circ} \mathrm{C}$ em meio TM modificado + Rodamina B. 


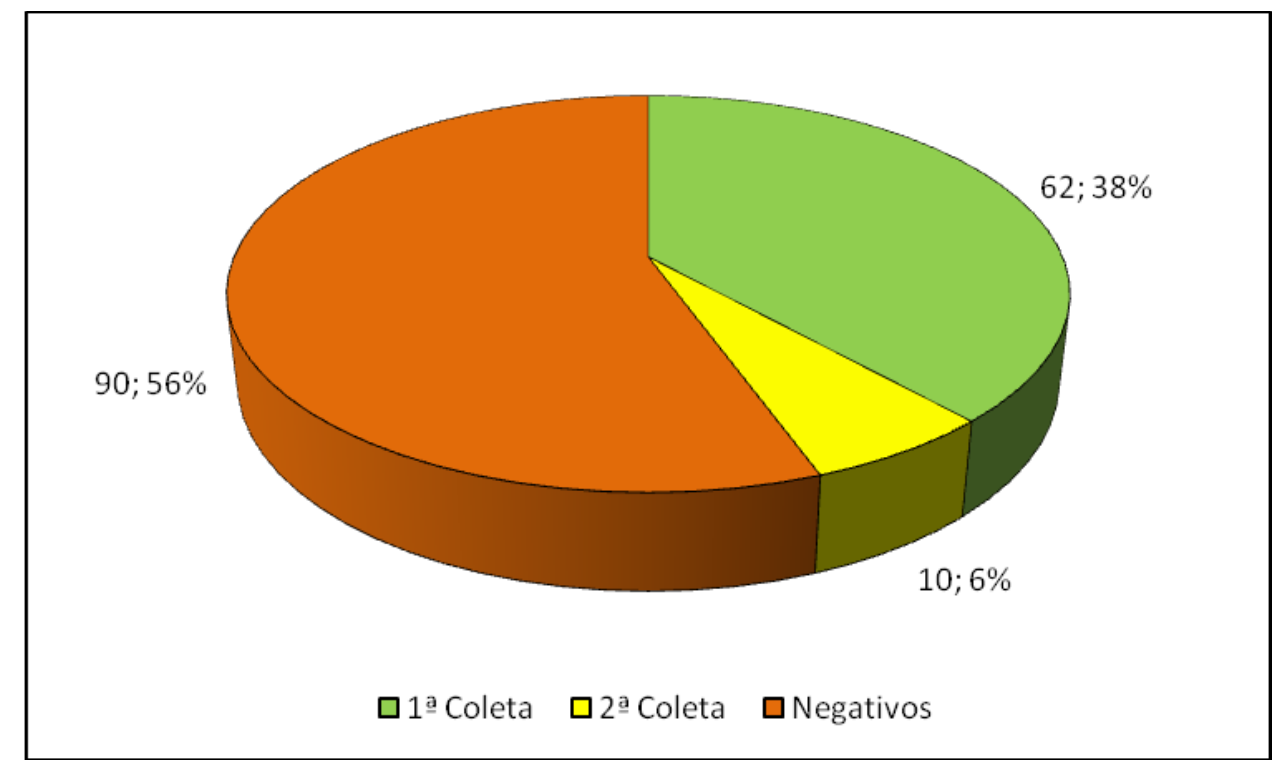

Figura 5. Positivos no High Throughput Screening de lipase.

\subsubsection{Confirmação da produção de lipase}

Dos 72 isolados avaliados individualmente (Figura 6), 40 representantes da primeira coleta e cinco da segunda coleta tiveram atividade lipolítica confirmada (Figura 7).

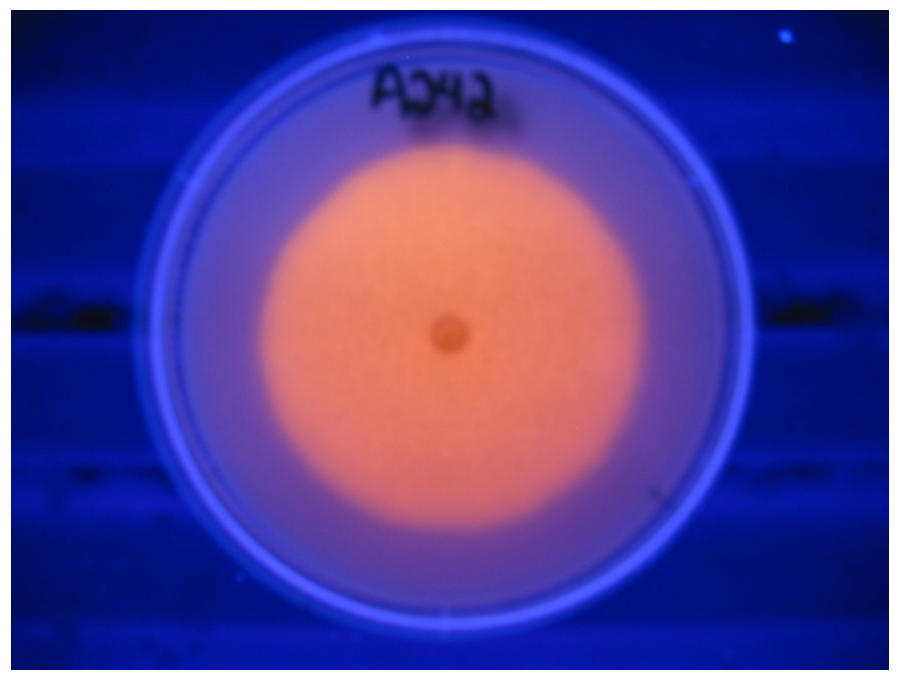

Figura 6. Visualização do resultado positivo no teste de confirmação da produção de lipase após 48 horas de incubação a $28^{\circ} \mathrm{C}$ em meio TM modificado + Rodamina B. 


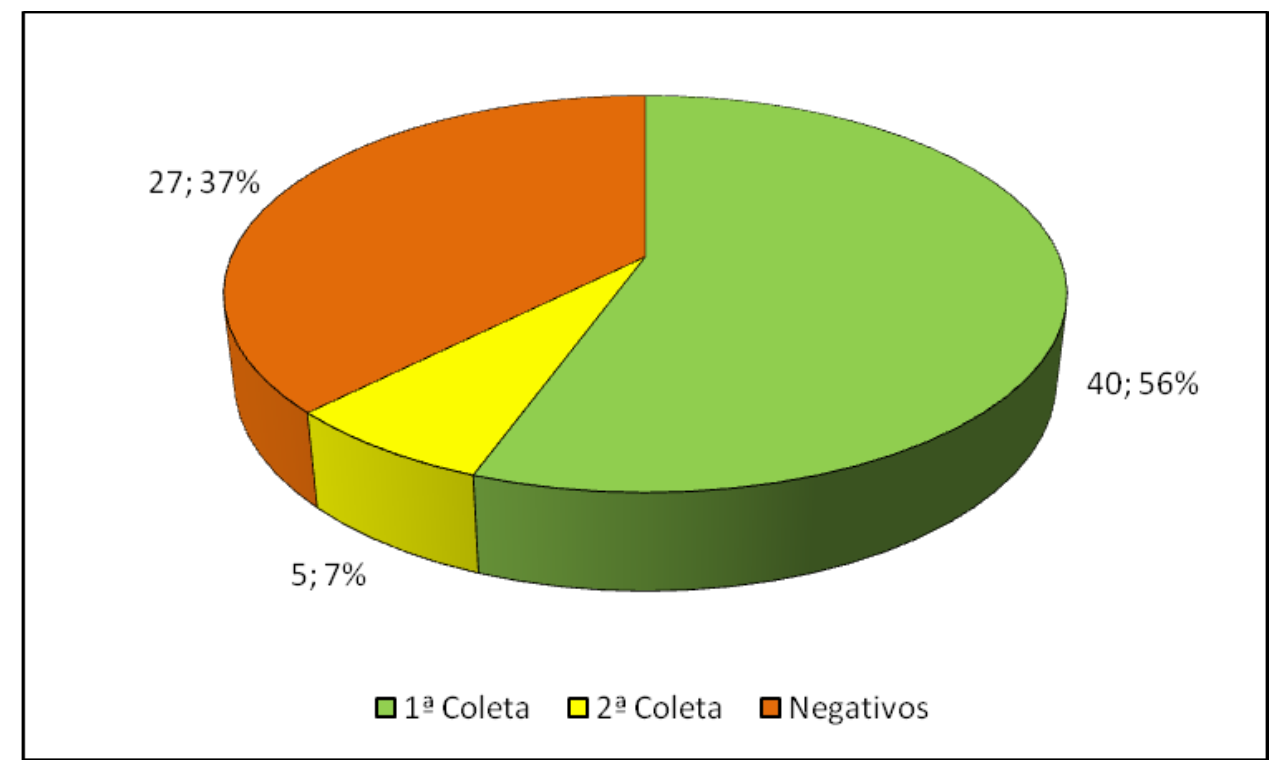

Figura 7. Positivos no teste de confirmação da produção de lipase.

No total 45 isolados positivos no HTS tiveram o resultado confirmado, cerca de $28 \%$ dos isolados selecionados para avaliação da atividade lipolítica (Figura 8). Estes resultados sugerem que a produção de lipases é um caractere relativamente comum entre fungos derivados de ambiente marinho. Alguns isolados podem ter consumido preferencialmente outros compostos presentes no meio, como o extrato de levedura ou peptona, ou então a rodamina $\mathrm{B}$, visto que algumas placas mantidas em estufa por mais tempo além do teste apresentaram descoloração do meio e acúmulo de rodamina B nas colônias. Kouker e Jaeger (1987) também observaram o acúmulo de rodamina B em colônias da bactéria Escherichia coli não-produtoras de lipase. Savitha et al. (2007) verificaram que alguns isolados de Aspergillus e Mucor só apresentaram atividade de lipase quando estava presente no meio um dos óleos que avaliaram. Em meio contendo somente glicose como fonte de carbono os extratos não apresentaram atividade de lipase, o que sugere que os óleos induzem a produção da enzima e ela não é normalmente produzida se há alguma fonte de carbono preferencial no meio. Entretanto, Roberts, Morrison III e Robertson (1987) verificaram que a presença de óleo de girassol no meio inibia, induzia ou não surtia efeito algum sobre a produção de lipase dependendo do fungo avaliado.

A metodologia de High Throughput Screening utilizada permitiu a triagem inicial dos 162 fungos utilizados no presente estudo. Métodos de triagem de alto desempenho são importantes em estudos de bioprospecção onde a triagem de um grande número de isolados pode ser feita rapidamente, poupando assim tempo e recursos dentro do laboratório. 
Entretanto, os resultados obtidos no presente estudo demonstram a necessidade de se realizar ensaios adicionais de produção de lipases pelos fungos selecionados, visto que, mais de um terço dos positivos no HTS não tiveram a atividade confirmada individualmente nas mesmas condições.

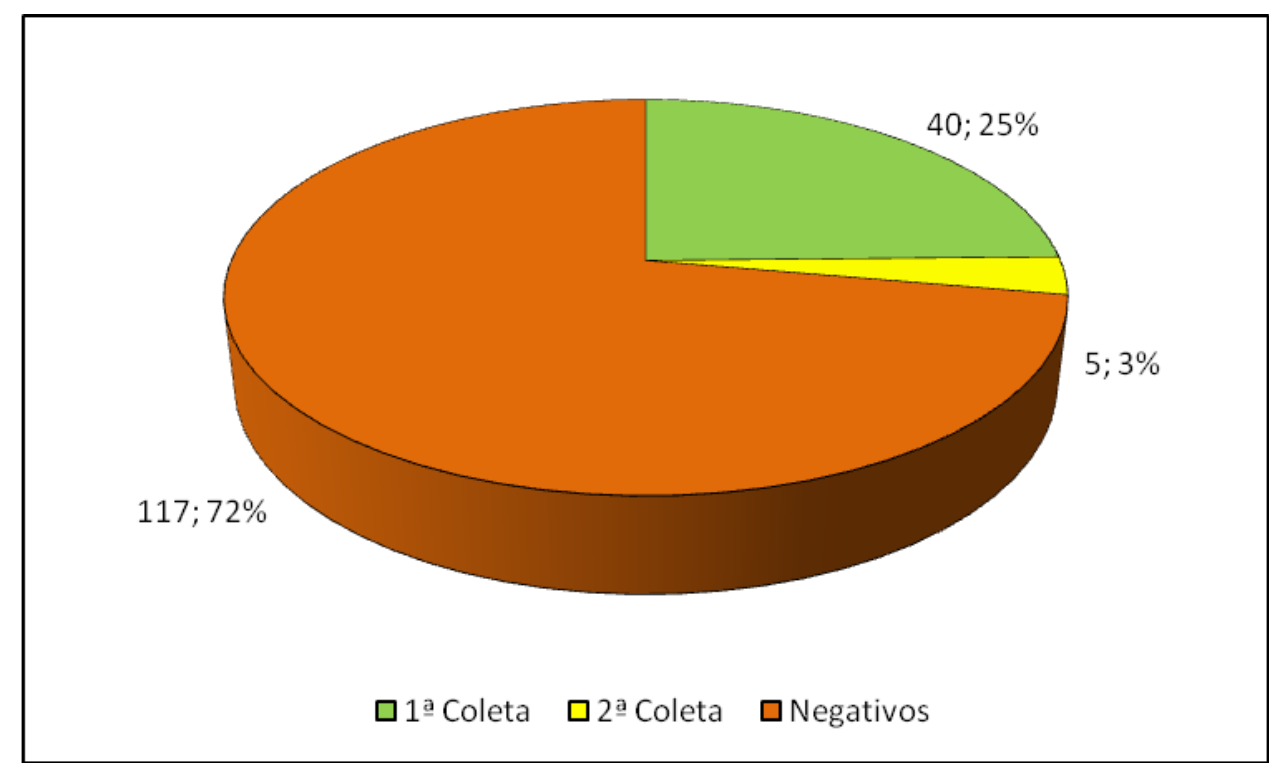

Figura 8. Isolados selecionados para avaliação da atividade lipolítica com resultado positivo confirmado.

Alguns dos fungos produtores de lipases derivados da primeira coleta foram preliminarmente identificados por Menezes et al. (2010) como pertencentes aos gêneros Acremonium, Aspergillus, Bionectria, Cladosporium, Eutypella, Fusarium, Hydropisphaera, Microsphaeropsis, Penicillium, Phomopsis, Rhizopus e Trichoderma, muitos dos quais são gêneros conhecidos por apresentarem representantes produtores de lipase (HASAN; SHAH; HAMEED, 2006; HOUDE; KADEMI; LEBLANC, 2004; JOSEPH et al., 2007; SAVITHA et al., 2007; SAXENA et al., 1999; SCHMID; VERGER, 1998; SEITZ, 1974; SHARMA; CHISTI; BANERJEE, 2001).

A ascídia Didemnum sp. foi o macro-organismo que apresentou maior número de isolados produtores de lipase, totalizando 14. As esponjas Dragmacidon reticulata e Amphimedon viridis também apresentaram grande número de produtores de lipase, 12 e 10, respectivamente. A esponja Mycale laxissima derivou quatro isolados produtores de lipase. Os quatro macro-organismos que apresentaram maior número de isolados produtores de lipase foram obtidos na primeira coleta (Figura 9). 


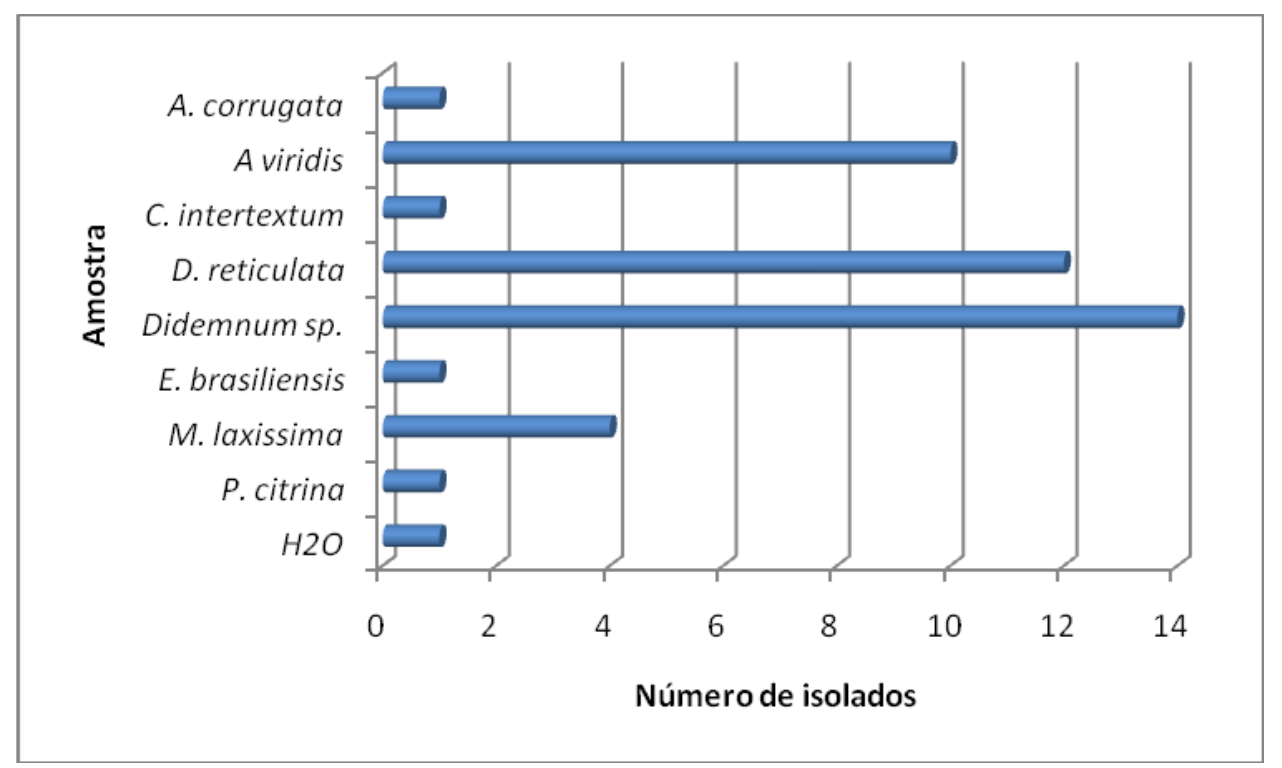

Figura 9. Isolados produtores de lipase por amostra.

O meio de isolamento que derivou o maior número de isolados produtores de lipase foi o meio Agar Malte (MS), meios estes que foram utilizados na primeira coleta. No total foram 22 isolados. Em segundo lugar ficou o meio TM, utilizado em ambas as coletas (Figura 10). Juntos os dois meios totalizaram 32 isolados produtores de lipase, sendo que destes cinco são da segunda coleta. A maioria dos fungos da primeira coleta foi isolada a partir destes dois meios, o que explica o fato dos quatro macro-organimos da primeira coleta terem apresentado o maior número de produtores.

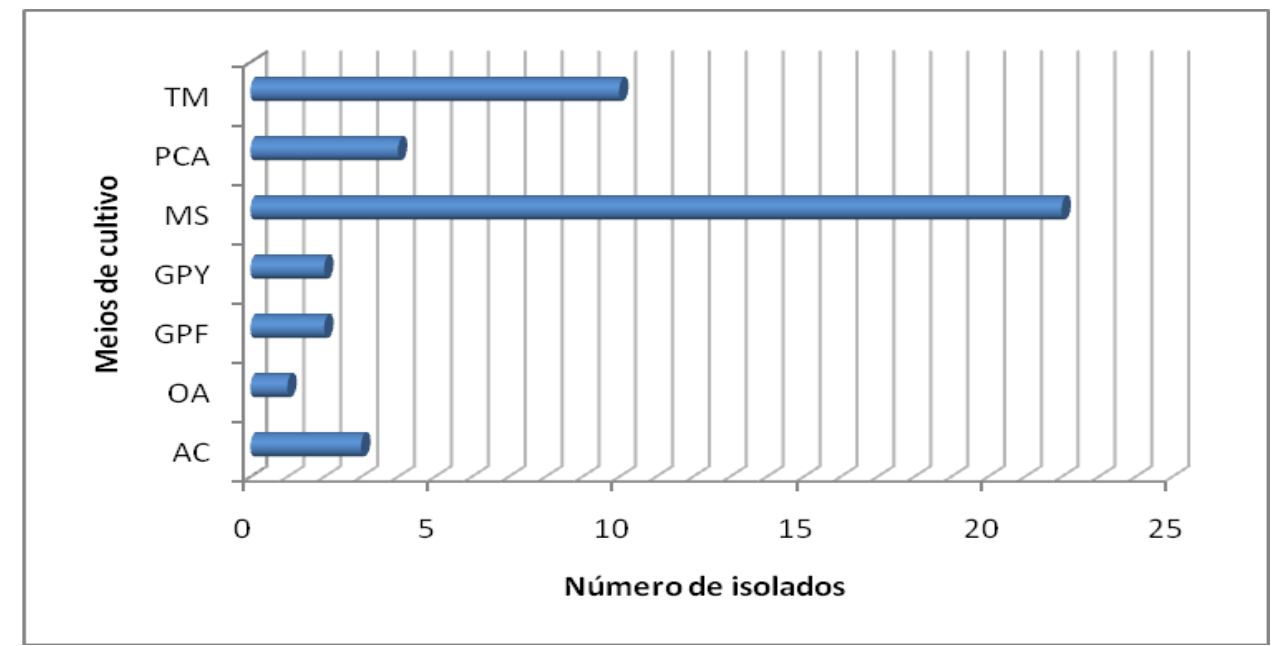

Figura 10. Isolados produtores de lipase e meios de isolamento. OA - Agar Aveia; PCA - Agar Cenoura Batata; MS - Agar Malte/Soja; TM - Meio de Tubaki; AC - Agar Celulose; GPF - Meio de Fubá e GPY - Meio Glicose, Peptona, Extrato de Levedura. 


\subsubsection{Quantificação da atividade lipolítica e caracterização taxonômica}

A grande maioria dos fungos que tiveram a produção de lipases confirmada após os experimentos de triagem apresentou atividade lipolítica muito baixa ou ausente. A metodologia de quantificação empregada pode não ter sido eficiente para estes isolados, ou estes não foram capazes de produzir lipase nas condições do teste de quantificação. Foi empregado o uso de meio líquido para produção da enzima. $\mathrm{Na}$ etapa de screening da atividade lipolítica os testes foram realizados em meio sólido. Esta mudança pode ter alterado de alguma forma o metabolismo e a produção de lipases pelos isolados, uma vez que originalmente se encontravam aderidos a superfícies no interior dos invertebrados de origem. Outra hipótese é a de que, caso os fungos tenham produzido lipase, esta pode não ter sido capaz de degradar o substrato sintético utilizado no teste.

Os resultados de absorbância das amostras dos 45 isolados lipolíticos analisados foram convertidos em U (unidades de enzima) com base na equação derivada do Gráfico da Figura 11.

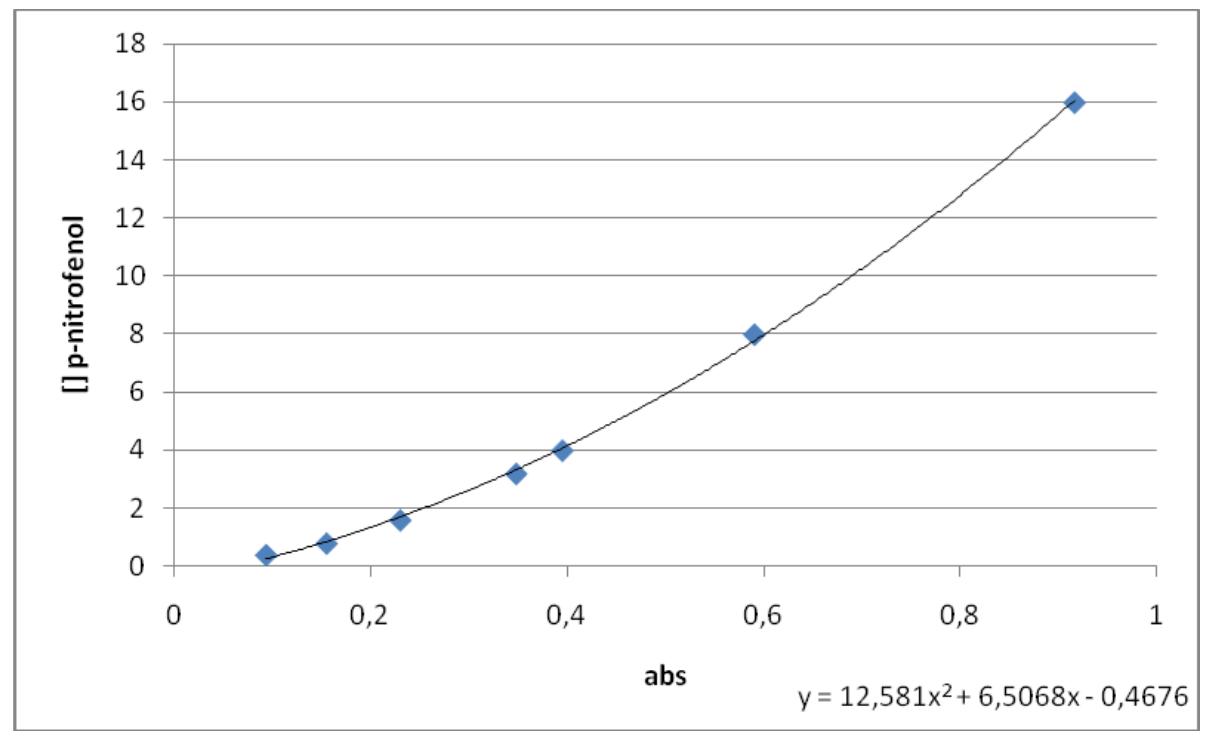

Figura 11 - Gráfico padrão de absorbância; p-nitrofenol 0,4 - 16,0 بmoles a 410nm

Sete isolados foram capazes de produzir lipases em quantidades maiores do que 1,0 U em pH 8,0 (Tabela 3). Estes isolados, preliminarmente identificados (taxonomia molecular) de acordo com Menezes et al. (2010), foram submetidos a análises taxonômicas convencionais (macro e micro-morfologia) visando identificação mais acurada e foram depositados na Coleção Brasileira de Micro-organismos de Ambiente e Indústria (CBMAI) sob os números de acesso listados na Tabela 3. 
Após análise morfológica o isolado CBMAI 1227 foi confirmado como sendo um Fusarium sp., apresentando macro-conídios característicos do gênero (NELSON; TOUSSOUN; MARASAS, 1983). Os dois representantes de Trichoderma spp. (CBMAI 1229 e CBMAI 1230) tiveram o gênero confirmado com base nas características típicas de crescimento em meio de cultura e de suas estruturas reprodutivas (DOMSCH; GAMS; ANDERSON, 1980). A especiação de fungos pertencentes aos gêneros Fusarium e Trichoderma é uma atividade de difícil execução. Desta forma, os fungos lipolíticos CBMAI 1227, CBMAI 1229 e CBMAI 1230 foram identificados em nível de gênero.

Dois isolados (CBMAI 1228 e CBMAI 1231), caracterizados por meio de taxonomia molecular como Aspergillus sp., foram identificados com base em dados morfológicos como A. parasiticus (SAMSON; HOEKSTRA; FRISVAD, 2002). Outro representante do gênero Aspergillus (CBMAI 1232) apresentou morfologia similar a do fungo A. niger, contudo os dados morfológicos não permitiram a confirmação da espécie, sendo este identificado como Aspergillus cf. niger (HOOG et al., 2000; SAMSON; HOEKSTRA; FRISVAD, 2002).

O fungo CBMAI 1233, molecularmente caracterizado como Penicillium cf. citrinum teve a espécie confirmada após as análises de macro e micro-morfologia (PITT, 1979).

Tabela 3 - Isolados com melhores resultados de atividade lipolítica em pH 8,0, número de acesso na CBMAI, dados taxonômicos e de origem.

\begin{tabular}{|c|c|c|c|c|c|c|}
\hline $\begin{array}{c}\text { Número } \\
\text { de acesso }\end{array}$ & $\begin{array}{c}\text { ID } \\
\text { Molecular }{ }^{\text {b }}\end{array}$ & $\begin{array}{c}\text { ID } \\
\text { Morfológica }\end{array}$ & ID Final & $\begin{array}{c}\text { Amostra } \\
\text { de origem }\end{array}$ & $\begin{array}{c}U^{\mathrm{c}} \\
\mathrm{pH} \mathrm{8,0}\end{array}$ & $\begin{array}{c}U^{c} \\
\text { pH 6,0 }\end{array}$ \\
\hline $\begin{array}{l}\text { CBMAI } 1227 \\
(152)^{\mathrm{a}}\end{array}$ & Fusarium sp. & Fusarium sp. & Fusarium sp. & ML & 23,1 & 0,7 \\
\hline $\begin{array}{l}\text { CBMAI } 1228 \\
\left(^{(79)^{\mathrm{a}}}\right.\end{array}$ & Aspergillus sp. & A. parasiticus & A. parasiticus & DR & 12,7 & 2,1 \\
\hline $\begin{array}{l}\text { CBMAI } 1229 \\
\left(^{\text {(PCTM 08) }}{ }^{a}\right.\end{array}$ & ND & Trichoderma sp. & Trichoderma sp. & $\mathrm{PC}$ & 12,2 & 3,0 \\
\hline $\begin{array}{l}\text { CBMAI } 1230 \\
(209)^{\mathrm{a}}\end{array}$ & Trichoderma sp. & Trichoderma sp. & Trichoderma sp. & DR & 2,9 & 0,5 \\
\hline $\begin{array}{l}\text { CBMAI 1231 } \\
(296)^{\mathrm{a}}\end{array}$ & Aspergillus sp. & A. parasiticus & A. parasiticus & DR & 2,1 & 0,5 \\
\hline $\begin{array}{c}\text { CBMAI } 1232 \\
(80)^{\mathrm{a}}\end{array}$ & Aspergillus sp. & $\begin{array}{c}\text { Aspergillus cf. } \\
\text { niger }\end{array}$ & Aspergillus cf. niger & DR & 1,7 & 2,4 \\
\hline $\begin{array}{c}\text { CBMAI } 1233 \\
\left(^{(19)^{a}}\right.\end{array}$ & $\begin{array}{l}\text { Penicillium } \mathrm{cf} . \\
\text { citrinum }\end{array}$ & P. citrinum & P. citrinum & Dsp & 1,1 & 0,1 \\
\hline \multicolumn{7}{|c|}{$\begin{array}{l}{ }^{\text {a }} \text { Código de isolamento } \\
\text { b Fonte: Menezes et al. }(2010) \\
{ }^{c} \text { Uma unidade de lipase (U) é definida como a quantidade de enzima que libera um } \mu \text { mol de } \\
\text { p-nitrofenol por minuto } \\
\text { ND: Não determinado }\end{array}$} \\
\hline
\end{tabular}


Maria et al. (2005) encontraram representantes de Acremonium sp., Aspergillus sp. e Fusarium sp. produtores de lipase e outras enzimas, isolados de mangue, ambiente de elevada salinidade. Assim como as linhagens obtidas no presente estudo, estes isolados não são fungos marinhos obrigatórios.

Os resultados do presente estudo demonstraram claramente que em $\mathrm{pH}$ levemente alcalino $(\mathrm{pH} \mathrm{8,0)}$ a atividade lipolítica é mais intensa, como verificado também por Savitha et al. (2007) para um isolado do gênero Mucor e por Maia et al. (1999) para a lipase de Fusarium solani FS1. De Oliveira et al. (2009) obtiveram o mesmo resultado para a lipase de Fusarium sp., que também apresentou potencial para aplicação na produção de biodiesel. Este resultado é particularmente interessante, pois uma das características desejáveis que as lipases comerciais devem apresentar é a tolerância a pH alcalino, pela larga aplicação que tem na indústria de detergentes e lavanderia. A maioria das lipases descritas até o momento são ativas em pH neutro (SAVITHA et al., 2007). O representante de Fusarium sp. avaliado no presente estudo foi o que apresentou maior atividade lipolítica em $\mathrm{pH} 8,0$, e a atividade caiu drasticamente em pH 6,0. Savitha et al. (2007) e Maia et al. (1999) obtiveram resultados semelhantes para um isolado de Mucor sp. e Fusarium solani, respectivamente.

Saxena et al. (2003) também obtiveram resultados de atividade lipolítica estável em pH alcalino (até pH 9,0) por Aspergillus carneus. Estudos realizados por Pera et al. (2006) demonstraram que, para os extratos brutos de lipase de Aspergillus niger produzidos na presença de óleo de oliva, a atividade lipolítica manteve-se estável na faixa de pH 2,0 - 10,0. Em contrapartida, foi verificado que os extratos brutos produzidos sem adição de óleo de oliva tiveram um decréscimo em todas as faixas de $\mathrm{pH}$, evidenciando comportamento diferente entre os dois extratos brutos, dependendo da fonte de carbono utilizada. Em adição, Shu, Yang e Yan (2007) também verificaram produção de lipase altamente estável em pH 2,0 - 9,0 por Aspergillus niger e Savitha e Ratledge (1992) obtiveram uma lipase alcalofilica de Aspergillus flavipes com $\mathrm{pH}$ ótimo de 8,8 .

Rajesh et al. (2010) avaliaram a produção de lipase por um isolado de Trichoderma reesei em meio contendo azeite de oliva. Este, diferentemente dos isolados de Trichoderma sp. CBMAI 1229 do presente trabalho capaz de produzir lipase $(12,2 \mathrm{U})$ em $\mathrm{pH} 8,0$, apresentou atividade ótima $(4,23 \mathrm{U} / \mathrm{mL}) \mathrm{em}$ pH ácido $(5,0)$. Em adição, Kashmiri, Adnan e Butt (2006) verificaram atividade de lipase extracelular de 7,3 U/mL por um isolado de Trichoderma viride em meio contendo azeite de oliva e $\mathrm{pH}$ neutro. 
Pimentel et al. (1997) reportaram a produção de uma lipase de Penicillium citrinum que apresentou melhor atividade em meio contendo azeite de oliva em comparação com outros óleos avaliados. Entretanto, esta enzima se manteve estável em pH 6,0 e não apresentou estabilidade em $\mathrm{pH} 8,0$, contrastando com os resultados obtidos neste estudo. Os autores também verificaram que a atividade enzimática diminui gradativamente com o aumento da concentração de potássio no meio. Em meio com concentração de $100 \mathrm{mM}$ de potássio a atividade enzimática foi muito baixa ( $2 \mathrm{U} / \mathrm{L})$ se comparada aos meios com menores concentrações $(1 \mathrm{mM}-1585 \mathrm{U} / \mathrm{L} ; 10 \mathrm{mM}-1290 \mathrm{U} / \mathrm{L} ; 30 \mathrm{mM}$ - $1238 \mathrm{U} / \mathrm{L} ; 50 \mathrm{mM}$ - $195 \mathrm{U} / \mathrm{L})$. Pimentel et al. (2006) verificaram que a lipase de um isolado de Penicillium citrinum, quando imobilizada, mantinha seu ótimo de $\mathrm{pH}$ em 8,0-8,5 e podia ser reutilizada até cinco vezes mantendo $75 \%$ de sua atividade inicial. Esta enzima se mostrou capaz de catalisar a síntese de trioleína a partir de azeite de oliva e glicerol em meio sem adição de solventes orgânicos.

No presente estudo o tampão empregado na quantificação da atividade lipolítica continha fosfato de sódio, e o meio para produção da enzima também. A presença de fosfato pode ter contribuído para inibição da atividade lipolítica de alguns dos isolados avaliados. Pimentel et al. (1997) também verificaram que, em meio contendo extrato de levedura, a lipase produzida por Penicillium citrinum apresentou atividade específica menor (4,9 U/mg de proteínas) se comparada a enzima produzida em meio sem o extrato (7,8 U/mg de proteínas). O meio em que foi realizada a produção de enzima no presente estudo também continha extrato de levedura, o que pode ter contribuído para a redução da atividade da lipase de alguns isolados. Estes dados sugerem que uma avaliação mais acurada das condições ideais para produção e quantificação da atividade de lipases por fungos recuperados de ambientes marinhos deve ser realizada.

Maliszewska e Mastalerz (1992) reportaram uma lipase produzida por Penicillium citrinum que teve atividade extracelular aumentada em seis vezes na presença de azeite de oliva se comparada ao meio basal utilizado. Esta enzima apresentou ótimo de pH de 7,2 mas se manteve estável em $\mathrm{pH}$ 5,0-7,0. Os autores também verificaram que a presença de $\mathrm{NaCl}$ e $\mathrm{KCl}$ em concentrações de $1 \mathrm{M}$ no meio não afetaram a atividade da enzima, e ferro, magnésio e cálcio inibiram a atividade - íons estes que estavam presentes na formulação do meio empregado para a produção da enzima no presente estudo, e podem ter interferido na atividade lipolítica de alguns dos fungos avaliados. 
Três dos fungos filamentosos selecionados, representantes de Fusarium sp. CBMAI 1227, Aspergillus parasiticus CBMAI 1228 e Trichoderma sp. CBMAI 1229 apresentaram atividade lipolítica semelhante ou superior a muitos dos produtores de lipases comerciais, como apresentado por Saxena et al. (1999) e Schmid e Verger (1998). O fungo Fusarium sp. CBMAI 1227 demonstrou atividade consideravelmente maior $(23,1 \mathrm{U})$ do que a quantidade verificada em representantes de Candida sp. (11-14 U), leveduras que estão entre os microorganismos mais largamente aplicados na produção industrial de lipases (DE MARÍA et al., 2005; SCHMID; VERGER, 1998). Estes valores de atividade lipolítica justificam a realização de estudos adicionais de purificação e caracterização bioquímica destas enzimas, bem como a caracterização dos genes que codificam para a produção das lipases e viabilidade de aplicação destes micro-organismos e de suas lipases em escala industrial.

As linhagens se mostram alvos de interesse para estudos futuros, uma vez que lipases ativas em $\mathrm{pH}$ alcalino encontram aplicação em enorme escala na indústria de detergentes e aditivos para lavanderia (SAVITHA et al., 2007). Por estarem naturalmente adaptadas a salinidade marinha, apresentam potencial para aplicação em biorremediação de derramamentos de petróleo nos oceanos (MacGILLIVRAY; SHIARIS, 1993). Em adição, acredita-se que a água do mar, que é naturalmente salina e mais próxima quimicamente do plasma do sangue humano, pode nos prover com produtos de origem microbiana, particularmente enzimas, que poderiam ser mais seguros ou apresentar menos toxicidade ou efeitos colaterais nas aplicações terapêuticas em humanos (SABU, 2003).

\subsection{Atividade emulsificante}

Não houve emulsificação do azeite de oliva pelo extrato de nenhum dos isolados. Foi verificada uma pequena emulsão nos testes contendo óleo diesel pelo extrato do fungo Trichoderma sp. CBMAI 1229, porém esta correspondeu a cerca de um milímetro de altura no tubo, cerca de $9 \%$ de emulsificação do volume de óleo. O mesmo correu para os fungos Trichoderma sp. CBMAI 1229 e Aspergillus parasiticus CBMAI 1228 no teste frente ao nhexadecano.

Segundo Bosch et al. (1988), são significativos os extratos capazes de formarem emulsão correspondente a no mínimo $40 \%$ do volume de óleo contido no tubo, e estáveis por 24 horas. Mesmo que insignificantes as emulsões se mantiveram estáveis após 24h. Os 
resultados sugerem que estudos mais aprofundados a respeito dos mecanismos de produção e ação de emulsificantes de fungos filamentosos derivados de ambiente marinho devem ser realizados. 


\section{CONCLUSÕES}

- O método de seleção dos fungos filamentosos derivados marinhos lipolíticos, baseado em triagem de alto desempenho e confirmação individual, foi empregado com sucesso no presente estudo, resultando na obtenção de 45 fungos lipolíticos (28\% do total de 162 isolados avaliados);

- Os invertebrados marinhos Didemnum sp., Dragmacidon reticulata e Amphimedon viridis se mostraram fontes potenciais de fungos filamentosos com atividade lipolítica;

- Os resultados de quantificação da atividade lipolítica sugerem que fungos filamentosos derivados de ambientes marinhos tem maior potencial para produção de lipases estáveis em $\mathrm{pH}$ alcalino do que ácido;

- Os fungos Fusarium sp. CBMAI 1227, Aspergillus parasiticus CBMAI 1228 e Trichoderma sp. CBMAI 1229 apresentaram atividade lipolítica expressiva em pH alcalino;

- Nas condições em que foram avaliados, os fungos Fusarium sp. CBMAI 1227, Aspergillus parasiticus CBMAI 1228 e Trichoderma sp. CBMAI 1229 não apresentaram atividade emulsificante signficativa, justificando a realização de mais estudos acerca da produção destes compostos por fungos filamentosos de origem marinha;

- Os resultados do presente estudo demonstram o potencial dos fungos derivados de ambiente marinho para aplicação biotecnológica e estimulam novos estudos de caracterização enzimática, detecção e caracterização de genes que codificam para a produção das lipases, bem como de otimização e produção destas enzimas em escala industrial. 


\section{REFERENCIAS $^{1}$}

ABARCA, M. L.; ACCENSI, F.; CANO, J.; CABAÑES, F. J. Taxonomy and significance of Black aspergilli. Antonie van Leeuwenhoek, v. 86, n. 1, p. 33-49, 2004.

ABLITZ, P.; FUKUSHIMA, K.; TAKIZAWA, K.; NISHIMURA, K. Identification of pathogenic dematiaceous fungi and related taxa based on large subunit ribosomal DNA D1/D2 domain sequence analysis. FEMS Immunology and Medical Microbiology, v. 40, n. 1, p. 41-49, 2004.

ADENKUNLE, A. A.; ADEBAMBO, O. A. Petroleum hydrocarbon utilization by fungi isolated from Detarium senegalense (J. F. Gmelin) seeds. Journal of American Science, Lansing, v. 3, n. 1, p. 69-76, 2007.

ALVES, A. C.; CARDOSO, J. J. F.; ALMEIDA, M. A. P.; MELO, C. K.; LOUZEIRO, H. C.; CÁRDIAS, H. T. C. Reaproveitamento de lipase imobilizada na transesterificação do óleo de babaçu. In: CONGRESSO DA REDE BRASILEIRA DE TECNOLOGIA DO BIODIESEL, 1., 2006, Brasília. Anais... Brasília: MCT/ABIPITI, 2006. p. 85-89.

ATLAS, R. M. Microbial degradation of petroleum hydrocarbons: an environmental perspective. Microbiological Reviews, v. 45, n. 1, p. 180-209, 1981.

BAHARUM, S. N.; BENG, E. K.; MOKHTAR, M. A. A. Marine microorganisms: potential applications and challenges. Journal of Biological Sciences, v. 10, n. 6, p. 555-564, 2010.

BERLINCK, R. G. S.; HAJDU, E.; DA ROCHA, R. M.; DE OLIVEIRA, J. H. H. L.; HERNÁNDEZ, I. L. C.; SELEGHIM, M. H. R.; GRANATO, A. C.; DE ALMEIDA, É. V. R.; NUÑEZ, C. V.; MURICY, G.; PEIXINHO, S.; PESSOA, C.; MORAES, M. O.; CAVALCANTI, B. C.; NASCIMENTO, G. G. F.; THIEMANN, O.; SILVA, M.; SOUZA, A. O.; SILVA, C. L.; MINARINI, P. R. R. Challenges and rewards of research in marine natural products chemistry in Brazil. Journal of Natural Products, Columbus, v. 67, n. 3, p. 510$522,2004$.

BISEN, P. S.; SANODIYA, B. S.; THAKUR, G. S.; BAGHEL, R. K.; PRASAD, G. B. K. S. Biodiesel production with special emphasis on lipase-catalyzed transesterification. Biotechnology Letters, v. 32, p. 1019-1030, 2010.

\footnotetext{
${ }^{1}$ De acordo com: ASSOCIAÇÃO BRASILEIRA DE NORMAS TÉCNICAS. NBR 6023: Informação e documentação: referências: elaboração. Rio de Janeiro, 2002.
} 
BONUGLI-SANTOS, R. C. Avaliação do potencial biosurfactante de fungos filamentosos associados a cnidários marinhos com atividade de degradação de HPAs. Microbiologia in Foco, n. 7, p. 12-17, 2009.

BOSCH, M. P.; ROBERT, M.; MERCADÉ, M. E.; ESPUNY, M. J.; PARRA, J. L.; GUINEA, J. . Surface active compounds on microbial cultures. Tenside Surfactants Detergents, v. 25, n. 4, p. 208-211, 1988.

BUGNI, T. S.; IRELAND, C. M. Marine-derived fungi: a chemically and biologically diverse group of microorganisms. Natural Product Reports, v. 21, p. 143-163, 2004.

BULL, A. T.; WARD, A. C.; GOODFELLOW, M. Search and discovery strategies for biotechnology: the paradigm shift. Microbiology and Molecular Biology Reviews, v. 64, $\mathrm{n}$. 3, p. 573-606, 2000.

CAVALCANTI, E. D. C.; GUTARRA, M. L. E.; FREIRE, D. M. G.; CASTILHO, L. R.; SANT'ANNA JÚNIOR, G. L. Lipase production by solid-state fermentation in fixed-bed bioreactors. Brazilian Archives of Biology and Technology, v. 48, p. 79-84, 2005. Número especial.

CHOI, S.; HWANG, J. M.; KIM, S. I. A colorimetric microplate assay method for high throughput analysis of lipase activity. Journal of Biochemistry and Molecular Biology, v. 36, n. 4, p. 417-420, 2003.

CIRIGLIANO, M. C.; CARMAN, G. M. Isolation of a bioemulsifier from Candida lipolytica. Applied and Environmental Microbiology, v. 48, n. 4, p. 747-750, out. 1984.

COLIN, V. L.; BAIGORÍ, M. D.; PERA, L. M. Bioemulsifier production by Aspergillus niger MYA 135: presumptive role of iron and phosphate on emulsifying ability. World Journal of Microbiology and Biotechnology, 2010. Disponível em: $<$ http://www.springerlink.com/content/39g23u3t78800841/>. Acesso em: 8 jan. 2011.

COSTA NETO, P. R. Obtenção de ésteres alquílicos (biodiesel) por via enzimática a partir de óleo de soja. 2002. 152 f. Tese (Doutorado em Química) - Centro de Ciências Físicas e Matemáticas, Universidade Federal de Santa Catarina, Florianópolis, 2002.

CRUZ, L. J.; INSUA, M. M.; BAZ, J. P.; TRUJILLO, M.; RODRIGUEZ-MIAS, R. A.; OLIVEIRA, E.; GIRALT, E.; ALBERICIO, F.; CAÑEDO, L. M. IB-01212, a new cytotoxic cyclodepsipeptide isolated from the marine fungus Clonostachys sp. ESNA-A009. Journal of Organic Chemistry, v. 71, n. 9, p. 3335-3338, 2006. 
DAS, S.; LYLA, P. S.; KHAN, A. Marine microbial diversity and ecology: importance and future perspectives. Current Science, v. 90, n. 10, p. 1325-1335, 2006.

DAVIES-COLEMAN, M. T.; BEUKES, D. R. Ten years of marine natural product research at Rhodes university. South African Journal of Science, n. 100, p. 539-544, 2004.

DE HOOG, G. S.; GUARRO, J.; GENÉ, J.; FIGUERAS, M. J. Atlas of Clinical Fungi. Reus: Universitat Rovira i Virgili, 2000.

DE MARÍA, P. D.; CARBONI-OERLEMANS, C.; TUIN, B.; BARGEMAN, G.; VAN DER MEER, A.; VAN GEMERT, R. Biotechnological applications of Candida Antarctica lipase A: state-of-the-art. Journal of Molecular Catalysis B: Enzymatic, v. 37, p. 36-46, 2005.

DE OLIVEIRA, B. H.; CORADI, G. V.; NETO, P. O.; LIMA, V. M. G. Produção e caracterização de lipase produzida por Fusarium sp. e sua aplicação na produção de biodiesel. In: CONGRESSO DE INICIAÇÃO CIENTÍFICA DA UNESP, 21., 2009, São José do Rio Preto. Anais... São José do Rio Preto: Universidade Estadual Paulista, 2009.

DOMSCH, K. H.; GAMS, W.; ANDERSON, T-H. Compendium of Soil Fungi. London: Academic Press, 1980. 859 p.

FERRER, M.; PlOU, F. J.; NUERO, O. M.; REYES, F.; BALlESTEROS, A. Purification and properties of a lipase from Penicillium chrysogenum isolated from industrial wastes. Journal of Chemical Technology and Biotechnology, v. 75, p. 569-576, 2000.

GESNER, S.; COHEN, N.; ILAN, M.; YARDEN, O.; CARMELI, S. Pandangolide 1a, a metabolite of the sponge-associated fungus Cladosporium sp., and the absolute stereochemistry of Pandangolide 1 and iso-Cladospolide B. Journal of Natural Products, v. 68 , n. 9 , p. 1350-1353, 2005.

GUARRO, J.; GENÉ, J.; STCHIGEL, A. M. Developments in fungal taxonomy. Clinical Microbiology Reviews, v. 12, n. 3, p. 454-500, 1999.

HASAN, F.; SHAH, A. A.; HAMEED, A. Industrial applications of microbial lipases. Enzyme and Microbial Technology, v. 39, p. 235-251, 2006.

HÖLLER, U.; WRIGHT, A. D.; MATTHEE, G. F.; KONIG, G. M.; DRAEGER, S.; AUST, H.; SCHULZ, B. Fungi from marine sponges: diversity, biological activity and secondary metabolites. Mycological Research, v. 104, n. 11, p. 1354-1365, 2000. 
HOUDE, A.; KADEMI, A.; LEBLANC, D. Lipases and their industrial applications. Applied Biochemistry and Biotechnology, v. 118, n. 1-3, p. 155-170, 2004.

IMHOFF, J. F. New natural products from marine microorganisms. IFM-Geomar Report 2002-2004, p. 44-46, 2005.

JAEGER, K-E.; EGGERT, T. Lipases for biotechnology. Current Opinion in Biotechnology, v. 13, p. 390-397, 2002.

JAEGER, K-E.; REETZ, M. T. Microbial lipases form versatile tools for biotechnology. Trends in Biotechnology, v. 16, p. 396-403, 1998.

JENSEN, R. G.; MARKS, T. A.; SAMPUGNA, J.; QUINN, J. G.; CARPENTER, D. L. Purification of triglycerides with an alumina column. Lipids, v. 1, n. 6, p. 451-452, 1966.

JHA, R. K.; ZI-RONG, X. Biomedical compounds from marine organisms. Marine Drugs, v. 2, p. 123-146, 2004.

JOSEPH, B.; RAMTEKE, P. W.; THOMAS, G.; SHRIVASTAVA, N. Standard review coldactive microbial lipases: a versatile tool for industrial applications. Biotechnology and Molecular Biology Reviews, v. 2, n. 2, p. 39-48, 2007.

KASHMIRI, M. A.; ADNAN, A.; BUTT, B. W. Production, purification and partial characterization of lipase from Trichoderma viride. African Journal of Biotechnology, v. 5, n. 10, p. $878-882,2006$.

KELECOM, A. Secondary metabolites from marine microorganisms. Annals of the Brazilian Academy of Sciences, v. 74, n. 1, p. 151-170, 2002.

KIRK, P. W.; GORDON, A. S. Hydrocarbon degradation by filamentous marine higher fungi. Mycologia, v. 80, n. 6, p. 776-782, 1988.

KLICH, M. A.; PITT, J. I. A Laboratory Guide to Common Aspergillus Species And Their Teleomorphs. New South Wales: Commonwealth Scientific and Industrial Research Organization, 1988. $116 \mathrm{p}$.

KOBAYASHI, M.; KITAGAWA, I. Bioactive substances isolated from marine sponge, a miniature conglomerate of various organisms. Pure and Applied Chesmistry, v. 66, n. 4, p. 819-826, 1994. 
KÖNIG, G. M.; KEHRAUS, S.; SEIBERT, S. F.; ABDEL-LATEFF, A.; MÜLLER, D. Natural products from marine organisms and their associated microbes. ChemBioChem, v. 7, p. 229-238, 2006.

KOUKER, G.; JAEGER, K-E. Specific and sensitive plate assay for bacterial lipases. Applied and Environmental Microbiology, v. 53, n. 1, p. 211-213, 1987.

LEAHY, J. G.; COLWELL, R. R. Microbial degradation of hydrocarbons in the environment. Microbiological Reviews, v. 54, n. 3, p. 305-315, 1990.

LEMOS, J. L. S.; RIZZO, A. C.; MILLIOLI, V. S.; SORIANO, A. U.; SARQUIS, M. I. M.; SANTOS, R. Petroleum degradation by filamentous fungi. In: INTERNATIONAL PETROLEUM ENVIRONMENTAL CONFERENCE, 9., 2002, Albuquerque. Anais... Albuquerque: Integrated Petroleum Environmental Consortium, 2002.

LIPTON, A. P. Marine bioactive compounds and their applications in mariculture. Environmental Management Capacity Building Technical Assistance Project Environmental Information System Newsletter, v. 2, n. 4, p. 2-12, 2003.

LOBUGLIO, K. F.; TAYLOR, J. W. Phylogeny and PCR identification of the human pathogenic fungus Penicillium maeneffei. Journal of Clinical Microbiology, v. 33, n. 1, p. 85-89, 1995.

LUNA-VELASCO, M. A.; ESPARZA-GARCÍA, F.; CAÑÍZARES-VILLANUEVA, R. O.; RODRÍGUEZ-VÁZQUEZ, R. Production and properties of a bioemulsifier synthesized by phenanthrene-degrading Penicillium sp. Process Biochemistry, v. 42, p. 310-314, 2007.

MacGILLIVRAY, A. R.; SHIARIS, M. P. Biotransformation of polycyclic aromatic hydrocarbons by yeasts isolated from coastal sediments. Applied and Environmental Microbiology, v. 59, n. 5, p. 1613-1618, 1993.

MAIA, M. M. D.; DE MORAIS, M. M. C.; MORAIS JÚNIOR, M. A.; MELO, E. H. M.; LIMA FILHO, J. L. Production of extracellular lípase by the phytopathogenic fungus Fusarium solani FS1. Brazilian Journal of Microbiology, v. 30, n. 4, p. 304-309, 1999.

MALISZEWSKA, I.; MASTALERZ, P. Production and some properties of lipase from Penicillium citrinum. Enzyme and Microbial Technology, v. 14, n. 3, p. 190-193, 1992.

MANEERAT, S. Biosurfactants from marine microorganisms. Songklanakarin Journal of Science \& Technology, v. 27, n. 6, p. 1263-1272, 2005. 
MARSHALL, M. N.; COCOLIN, L.; MILLS, D. A.; VANDERGHEYNST, J. S. Evaluation of PCR primers for denaturing gradient gel electrophoresis analysis of fungal communities in compost. Journal of Applied Microbiology, v. 95, n. 5, p. 934-948, 2003.

MARTINS, V. G.; KALIL, S. J.; COSTA, J. A. V. Co-produção de lipase e biossurfactante em estado sólido para utilização em biorremediação de óleos vegetais e hidrocarbonetos. Química Nova, v. 31, n. 8, p. 1942-1947, 2008.

MAYER, A. M. S.; HAMANN, M. T. Marine Pharmacology in 2000: Marine Compounds with Antibacterial, Anticoagulant, Antifungal, Anti-inflammatory, Antimalarial, Antiplatelet, Antituberculosis, and Antiviral Activities; Affecting the Cardiovascular, Immune, and Nervous Systems and Other Miscellaneous Mechanisms of Action. Marine Biotechnology, v. 6, p. 37-52, 2004.

MAYER, A. M. S.; LEHMANN, V. K. B. Marine pharmacology in 1998: Marine Compounds with Antibacterial, Anticoagulant, Antifungal, Anti-inflammatory, Anthelmintic, Antiplatelet, Antiprotozoal, and Antiviral Activities; with actions on the Cardiovascular, Endocrine, Immune, and Nervous Systems; and other Miscellaneous Mechanisms of Action. The Pharmacologist, v. 42, n. 2, p. 62-69, 2000.

MENEZES, C. B. A.; BONUGLI-SANTOS, R. C.; MIQUELETTO, P. B.; PASSARINI, M. R. Z.; SILVA, C. H. D.; JUSTO, M. R.; LEAL, R. R.; FANTINATTI-GARBOGGINI, F.; OLIVEIRA, V. M.; BERLINCK, R. G. S.; SETTE, L. D. Microbial Diversity associated with algae, ascidians and sponges from the north coast of São Paulo state, Brasil. Microbiological Research, v. 165, n. 6, p. 466-482, 2010.

MUNN, C. B. Marine Microbiology: ecology \& applications. Londres: BIOS Scientific Publishers, 2004.

NELSON, L. A.; FOGLIA, T. A.; MARMER, W. N. Lipase-catalyzed production of biodiesel. Journal Of The American Oil Chemists' Society, v. 73, n. 8, p. 1191-1195, 1996.

NELSON, P. E.; TOUSSOUN, T. A.; MARASAS, W. F. O. Fusarium Species: an illustrated manual for identification. University Park: The Pennsylvania State University Press, 1983.

NERURKAR, A. S.; HINGURAO, K. S.; SUTHAR, H. G. Bioemulsifiers from marine microorganisms. Journal of Scientific \& Industrial Research, v. 68, p. 273-277, 2009.

PANG, K.; MITCHELL, J. I. Molecular approaches for assessing fungal diversity in marine substrata. Botanica Marina, v. 48, p. 332-347, 2005. 
PASSARINI, M. R. Z.; RODRIGUES, M. V. N.; DA SILVA, M.; SETTE, L. D. Marinederived filamentous fungi and their potential application for polycyclic aromatic hydrocarbon degradation. Marine Pollution Bulletin, 2010. In press.

PASTORE, G. M.; DA COSTA, V. S. R.; KOBLITZ, M. G. B. Purificação parcial e caracterização bioquímica de lipase extracelular produzida por nova linhagem de Rhizopus sp. Ciência e Tecnologia de Alimentos, v. 23, n. 2, p. 135-140, 2003.

PEINTNER, U.; MOSER, M. M.; THOMAS, K. A.; MANIMOHAN, P. First records of ectomycorrhizal Cortinarius species (Agaricales, Basidiomycetes) from tropical India and their phylogenetic position based on rDNA ITS sequences. Mycological Research, Amsterdam, v. 107, p. 485-494, 2003.

PERA, L. M.; ROMERO, C. M.; BAIGORI, M. D.; CASTRO, G. R. Catalytic properties o flipase extracts from Aspergillus niger. Food Technology and Biotechnology, v. 44, n. 2, p. 247-252, 2006.

PIMENTEL, M. C. B.; LEÃO, A. B. F.; MELO, E. H. M.; LEDINGHAM, W. M.; LIMA FILHO, J. L.; KENNEDY, J. F. Immobilization of Penicillium citrinum lipase on ferromagnetic azide-dacron. Biotechnology, v. 5, n. 3, p. 228-233, 2006.

PIMENTEL, M. C. B.; MELO, E. H. M.; LIMA FILHO, J. L.; LEDINGHAM, W. M.; DURÁN, N. Lipase from a brazilian strain Penicillium citrinum cultured in a simple and inexpensive medium - heat denaturarion, kinetics and $\mathrm{pH}$ stability. Applied Biochemistry and Biotechnology, v. 66, n. 2, p. 185-195, 1997.

PITT, J. I. The Genus Penicillium And Its Teleomorphic States Eupenicillium And Talaromyces. London: Academic Press, 1979. 634 p.

PRASANNARAI, K.; SRIDHAR, K. R. Diversity and abundance of higher marine fungi on woody substrates along the west coast of India. Current Science, v. 81, n. 3, p. 304-311, 2001 .

PROKSCH, P.; EBEL, R.; EDRADA, R. A.; SCHUPP, P.; LIN, W. H.; SUDARSONO; WRAY, V.; STEUBE, K. Detection of pharmacologically active natural products using ecology. Selected examples from Indopacific marine invertebrates and sponge-derived fungi. Pure and Applied Chemistry, v. 75, n. 2-3, p. 343-352, 2003.

PROSKOVÁ, A.; KOPICOVÁ, Z.; KUCERA, J.; SKARKOVÁ, L. Lipase-catalyzed transesterification of rendering plant fat - short communication. Research in Agricultural Engineering, v. 56, n. 3, p. 122-125, 2010. 
RAGHUKUMAR, C. Diversity and adaptations of deep-sea microorganisms. In:

SATYANARAYANA, T.; JOHRI, B. N. Microbial Diversity: Current Perspectives and Potential Applications, New Delhi: I. K. International Publishing House Pvt. Ltd., 2005. p. 123.

RAJESH, E. M.; ARTHE, R.; RAJENDRAN, R.; BALAKUMAR, C.; PRADEEPA, N.; ANITHA, S. Investigation of lipase production by Trichoderma reesei and optimization of production parameters. Electronic Journal of Environmental, Agricultural and Food Chemistry, v. 9, n. 7, p. 1177-1189, 2010.

RESEARCHERS study lipase applications. Journal of the American Oil Chemists' Society, v. 64, n. 9, p. 1234, 1987.

RHEINHEIMER, G. Microbiologia de las Aguas. 4. ed. Zaragoza: Acribia, 1987.

ROBERTS, R. G.; MORRISON III, W. H.; ROBERTSON, J. A. Extracellular lipase production by fungi from sunflower seed. Mycologia, v. 79, n. 2, p. 265-273, 1987.

RODRIGUES, R. C. Síntese de biodiesel através de transesterificação enzimática de óleos vegetais catalisada por lipase imobilizada por ligação covalente multipontual. 2009. 171 f. Tese (Doutorado em Engenharia Química) - Escola de Engenharia, Universidade Federal do Rio Grande do Sul, Porto Alegre, 2009.

SABU, A. Sources, properties and applications of microbial therapeutic enzymes. Indian Journal of Biotechnology, v. 2, n. 3, p. 334-341, 2003.

SAFFO, M. B. Distribution of endosymbiont Nephromyces giard within the ascidian family Molgulidae. Biology Bulletin, v. 162, p. 95-104, 1982.

SAMSON, R. A.; HOEKSTRA, E. S.; FRISVAD, J. C. Introduction to Food- and Airborne Fungi. 6th ed. Utrecht: Centraalbureau voor Schimmelcultures, 2002. 389 p.

SANDOVAL, G.; RIVERA, I.; CASAS, L.; SÁNCHEZ, I. Biodiesel synthesis from waste lipids catalyzed by immobilized lipases. In: CONGRESO NACIONAL DE BIOTECNOLOGÍA Y BIOINGENIERÍA 13., 2009, Acapulco. Trabajos... Acapulco: Sociedad Mexicana de Biotecnología y Bioingeniería, 2009.

SARUBBO, L. A.; DE LUNA, J. M.; CAMPOS-TAKAKI, G. M. C. Production and stability studies of the bioemulsifier obtained from a new strain of Candida glabrata UCP 1002. Electronic Journal of Biotechnology, v. 9, n. 4, p. 400-406, 2006. 
SAVITHA, J.; SRIVIDYA, S.; JAGAT, R.; PAYAL, P.; PRIYANKI, S.; RASHMI, G. W.; ROSHINI, K. T.; SHANTALA, Y. M. Identification of potential fungal strain(s) for the production of inducible, extracellular and alkalophilic lipase. African Journal of Biotechnology, v. 6, n. 5, p. 564-568, 2007.

SAVITHA, J.; RATLEDGE, C. An inducible, intracellular, alkalophilic lipase in Aspergillus flavipes grown on triacylglycerols. World Journal of Microbiology and Biotechnology, $\mathrm{v}$. 8, p. 129-131, 1992.

SAXENA, R. K.; GHOSH, P. K.; GUPTA, R.; DAVIDSON, W. S.; BRADOO, S.; GULATI, R. Microbial lipases: potential biocatalysts for the future industry. Current Science, Bangalore, v. 77, n. 1, p. 101-115, 1999.

SAXENA, R. K.; DAVIDSON, W. S.; SHEORAN, A.; GIRI, B. Purification and characterization of an alkaline thermostable lipase from Aspergillus carneus. Process Biochemistry, v. 39, p. 239-247, 2003.

SCHABEREITER-GURTNER, C.; PIÑAR, G.; LUBITZ, W.; RÖLLEKE, S. Analysis of fungal communities on historical church window glass by denaturing gradient gel eletrophoresis and phylogenetic 18 rDNA sequence analysis. Journal of Microbiological Methods, v. 47, p. 345-354, 2001.

SCHMID, R. D.; VERGER, R. Lipases: interfacial enzymes with attractive applications. Angewandte Chemie International Edition, v. 37, p. 1608-1633, 1998.

SEITZ, E. W. Industrial application of microbial lipases: a review. Journal of the American Oil Chemists' Society, v. 51, p. 12-16, 1974.

SHARMA, R.; CHISTI, Y.; BANERJEE, U. C. Production, purification, characterization, and applications of lipases. Biotechnology Advances, v. 19, p. 627-662, 2001.

SHIGEMORI, H.; KASAI, Y.; KOMATSU, K.; TSUDA, M.; MIKAMI, Y.; KOBAYASHI, J. Sporiolides A and B, new cytotoxic twelve-membered macrolides from a marine-derived fungus Cladosporium species. Marine Drugs, v. 2, p. 164-169, 2004.

SHIVAJI, S.; PRASAD, G. S. Antarctic yeasts: biodiversity and potential applications. In: SATYANARAYANA, T.; KUNZE, G. (Ed.). Yeast Biotechnology: Diversity and Applications. New Delhi: Springer Science, 2009. p. 3-18.

SHU, Z.; YANG, J.; YAN, Y. Purification and characterization of a lipase from Aspergillus niger F044. Chinese Journal of Biotechnology, v. 23, n. 1, p. 96-101, 2007. 
STERFLINGER, K.; PRILLINGER, H. Molecular taxonomy and biodiversity of rock fungal communities in an urban environment (Vienna, Austria). Antonie van Leeuwenhoek, v. 80, p. 275-286, 2001.

SUTAR, R.; DAVID, J. K.; GANESAN, K.; GHOSH, A. K.; SINGHI, S.; CHAKRABARTI, A.; BACHHAWAT, A. K. Comparasion of ITS and IGS regions for strain typing of clinical and non-clinical isolates of Pichia anomal. Journal of Medical Microbiology, v. 53, p. 1-5, 2004.

TAYLOR, M. W.; RADAX, R.; STEGER, D.; WAGNER, M. Sponge-associated microorganisms: evolution, ecology and biotechnological potential. Microbiology and Molecular Biology Reviews, v. 71, n. 2, p. 295-347, 2007.

THAKUR, N. L.; MÜLLER, W. E. G. Biotechnological potential of marine sponges. Current Science, v. 86, n. 11, p. 1506-1512, 2004.

VASCONCELLOS, S. P. Atividades enzimáticas e de biodegradação de microrganismos do petróleo da Bacia de Campos (Pampo Sul). 2006. 238 f. Tese (Doutorado em Ciências) - Instituto de Química, Universidade Estadual de Campinas, Campinas, 2006.

WANDREY, C.; LIESE, A.; KIHUMBU, D. Industrial biocatalysis: past, present and future. Organic Process Research and Development, v. 4, n. 4, p. 286-290, 2000.

WILLUMSEN, P. A.; KARLSON, U. Screening of bacteria, isolated from PAH-contaminated soils, for production of biosurfactants and bioemulsifiers. Biodegradation, v. 7, p. 415-423, 1997.

YOUSSEF, D. Marine biotechnology in Egypt. In: BIOACTIVE NATURAL PRODUCTS: CURRENT STATUS AND FUTURE SCENARIOS, 2007, Cairo. Abstracts... Cairo: National Research Center, 2007. p. 14. 


\section{ANEXOS - Tabelas}

TABELA A - Isolados com atividade de lipase confirmada.

\begin{tabular}{|c|c|c|}
\hline Isolado & Meio de isolamento & Amostra \\
\hline 5 & PCA & DSP \\
\hline 11 & PCA & Dsp \\
\hline 12 & PCA & DR \\
\hline 19 & TM & DSP \\
\hline 37 & MS & DR \\
\hline 43 & MS & $\mathrm{AV}$ \\
\hline 44 & MS & $\mathrm{AV}$ \\
\hline 72 & $\operatorname{MS}(2 \%)$ & ML \\
\hline 77 & $\mathrm{OA}$ & $\mathrm{AV}$ \\
\hline 79 & MS & DR \\
\hline 80 & MS & DR \\
\hline 81 & MS & $\mathrm{AV}$ \\
\hline 84 & TM & DR \\
\hline 86 & MS & $\mathrm{AV}$ \\
\hline 111 & MS & Dsp \\
\hline 119 & MS & $\mathrm{DR}$ \\
\hline 141 & TM & DR \\
\hline 152 & MS & ML \\
\hline 162 & MS & $\mathrm{AV}$ \\
\hline 163 & GPF & Dsp \\
\hline 186 & $\operatorname{MS}(3 \%)$ & Dsp \\
\hline 195 & $\mathrm{AC}$ & AV \\
\hline 209 & PCA & DR \\
\hline 223 & MS(f) & Dsp \\
\hline 236 & $\mathrm{TM}$ & Dsp \\
\hline 237 & $\operatorname{MS}(2 \%)$ & Dsp \\
\hline 238 & MS & Dsp \\
\hline 239 & MS & Dsp \\
\hline 242 & $\mathrm{AC}$ & AV \\
\hline 245 & TM & $\mathrm{AV}$ \\
\hline 258 & GPY & ND \\
\hline 261 & MS & Dsp \\
\hline 266 & $\mathrm{AC}$ & ML \\
\hline 271 & MS & ML \\
\hline 274 & MS & AV \\
\hline 276 & GPF & DSP \\
\hline 278 & GPY & Dsp \\
\hline 282 & MS & DR \\
\hline 290 & MS & DR \\
\hline
\end{tabular}




\begin{tabular}{ccc}
\hline 296 & ND & DR \\
\hline ACTM 051 & TM & AC \\
\hline CITM 042 & TM & CI \\
\hline EBTM 02 & TM & EB \\
\hline H2OTM 01 & TM & H2O \\
\hline PCTM 08 & TM & PC \\
\hline
\end{tabular}

ND = Não determinado

TABELA B - Valores de absorbância para construção do gráfico padrão da Figura 7.

\begin{tabular}{cccc}
\hline[] $\boldsymbol{\mu m o l} \mathbf{m}^{*}$ & Abs & Abs & Média \\
\hline 0,4 & 0,09 & 0,097 & 0,0935 \\
\hline 0,8 & 0,154 & 0,156 & 0,155 \\
\hline 1,6 & 0,226 & 0,234 & 0,23 \\
\hline 3,2 & 0,346 & 0,35 & 0,348 \\
\hline 4 & 0,395 & 0,395 & 0,395 \\
\hline 8 & 0,597 & 0,584 & 0,5905 \\
\hline 16 & 0,919 & 0,914 & 0,9165 \\
\hline
\end{tabular}

* p-nitrofenol

TABELA C - Isolados que apresentaram atividade lipolítica em pH 6,0.

\begin{tabular}{cccccc}
\hline Isolado & abs1 & abs2 & abs3 & Média & U \\
\hline PCTM 08 & 0,332 & 0,316 & 0,328 & 0,325333 & 3,0 \\
\hline 11 & 0,322 & 0,301 & 0,29 & 0,304333 & 2,7 \\
\hline 80 & 0,285 & 0,294 & 0,278 & 0,285667 & 2,4 \\
\hline 79 & 0,266 & 0,262 & 0,259 & 0,262333 & 2,1 \\
\hline 81 & 0,266 & 0,263 & 0,256 & 0,261667 & 2,1 \\
\hline 152 & 0,132 & 0,132 & 0,151 & 0,138333 & 0,7 \\
\hline 266 & 0,134 & 0,127 & 0,117 & 0,126 & 0,6 \\
\hline 209 & 0,134 & 0,137 & 0,103 & 0,124667 & 0,5 \\
\hline 296 & 0,125 & 0,115 & 0,13 & 0,123333 & 0,5 \\
\hline 236 & 0,096 & 0,116 & 0,115 & 0,109 & 0,4 \\
\hline 195 & 0,093 & 0,106 & 0,102 & 0,100333 & 0,3 \\
\hline 19 & 0,07 & 0,06 & 0,092 & 0,074 & 0,1 \\
\hline 141 & 0,075 & 0,071 & 0,07 & 0,072 & 0,1 \\
\hline
\end{tabular}

TABELA D - Isolados que apresentaram atividade lipolítica em pH 8,0.

\begin{tabular}{cccccc}
\hline Isolado & abs1 & abs2 & abs3 & Média & $\mathbf{U}$ \\
\hline 152 & 1,128 & 1,138 & 1,133 & 1,133 & 23,1 \\
\hline 79 & 0,769 & 0,786 & 0,833 & 0,796 & 12,7 \\
\hline
\end{tabular}




\begin{tabular}{cccccc}
\hline PCTM 08 & 0,758 & 0,767 & 0,806 & 0,777 & 12,2 \\
\hline 209 & 0,303 & 0,323 & 0,327 & 0,317667 & 2,9 \\
\hline 296 & 0,275 & 0,264 & 0,256 & 0,265 & 2,1 \\
\hline 80 & 0,242 & 0,209 & 0,233 & 0,228 & 1,7 \\
\hline 19 & 0,18 & 0,167 & 0,18 & 0,175667 & 1,1 \\
\hline 195 & 0,156 & 0,163 & 0,154 & 0,157667 & 0,9 \\
\hline 81 & 0,148 & 0,149 & 0,131 & 0,142667 & 0,7 \\
\hline 236 & 0,145 & 0,124 & 0,128 & 0,132333 & 0,6 \\
\hline 238 & 0,122 & 0,125 & 0,125 & 0,124 & 0,5 \\
\hline 266 & 0,115 & 0,109 & 0,129 & 0,117667 & 0,5 \\
\hline 77 & 0,118 & 0,101 & 0,104 & 0,107667 & 0,4 \\
\hline 162 & 0,093 & 0,094 & 0,094 & 0,093667 & 0,3 \\
\hline 11 & 0,096 & 0,089 & 0,088 & 0,091 & 0,2 \\
\hline 239 & 0,089 & 0,092 & 0,091 & 0,090667 & 0,2 \\
\hline 72 & 0,064 & 0,102 & 0,048 & 0,071333 & 0,1 \\
\hline 245 & 0,072 & 0,073 & 0,069 & 0,071333 & 0,1 \\
\hline 258 & 0,07 & 0,072 & 0,07 & 0,070667 & 0,1 \\
\hline
\end{tabular}

